\title{
CSF biomarkers for improved prognostic accuracy in acute CNS disease
}

\author{
Axel Petzold * \\ 03.09.2007
}

\begin{abstract}
Providing an accurate prognosis in patients suffering from acute CNS disease is difficult. The extent and location of the primary CNS injury is crucial for mortality and morbidity. Secondary injury adds considerably to the CNS insult. The prognosis in an individual patient depends on the combination of primary and secondary CNS damage together with systemic complications. The clinical challenge of an accurate prognosis is therefore aided by both quantitative techniques, able to estimate the degree of CNS damage and qualitative techniques, which identify the site of the lesion. Here the contribution of cerebrospinal fluid (CSF) biomarkers to improving the prognostic accuracy is reviewed. Firstly current definitions in biomarker research are introduced. Secondly the role of the blood brain barrier is discussed. Thirdly the physiological and anatomical constraints of the CSF are summarised. Fourthly following an overview on CSF biomarkers, cell-type specific CSF biomarkers and more global CSF biomarkers for parenchymal CNS damage are reviewed in detail. The release of these biomarkers from dying cells is illustrated by a video of a laser-dissected neuron. Finally, the evidence for improving prognostic accuracy is summarised and recommendations are made for future biomarker research.
\end{abstract}

*UCL Institute of Neurology, Department of Neuroimmunology, University College London; The Tavistock Intensive Care unit, The National Hospital for Neurology and Neurosurgery, University College London Hospitals (UCLH), Queen Square, London WC1N 3BG. 
Keywords 4-hydroxynonenal (HNE), Albumin, Alpha spectrin, Alpha(1)BG, Alpha-internexin, Amyloid beta peptide (ABP), Apolipoprotein E, Beta-tubulin, Beta-2-Microglobulin, Beta-APP, Beta-trace, Clusterin, Cystatin C, Endothelial differentiation, sphingolipid G-protein-coupled receptor 8 (EDG-8), Fatty acid binding proteins (FABPs), Ferritin, Free fatty acids (FFA), Glasgow Coma Score (GCS), Glial fibrillary acidic protein (GFAP), Glucose, Glutamate, Human kallikrein 6 (HK6), Hypocretin-1, Intermediate filaments, Isoprostanes, Lactate, Malondialdehyde (MDA), Myelin basic protein (MBP), Myelin-associated glycoprotein (MAG), Myelin-associated oligodendrocytic protein (MOBP), Myelin/oligodendrocyte glycoprotein (MOG), $\mathrm{N}$-acetyl aspartate (NAA), Neuronal thread protein AD7c (AD7c-NTP), Neural Cell Adhesion Molecule (NCAM), Nestin, Neurofilament (Nf), Nf heavy chain ( $\mathrm{NfH}$ ), Nf medium chain (NfM), Nf light chain (NfL), Neuronspecific enolase (NSE), Neurotrophins, Nitric oxide (NO), Oligodendrocyte/myelin glycoprotein (OMgp), Proteolipid protein (PLP), Pigments, Prion Protein cellular (PrPc), Protein 14-3-3, Proteolipid protein (PLP), Pyruvate, S100B, SFas (sCD95), Tau, Taurine, Ubiquitin, Vimentin 


\section{Introduction}

Neurocritical medicine provides care to some of the most vulnerable patients. In most patients the level of consciousness is impaired to the level of coma, either because of the injury or secondary to deep sedation. Assessing these patients is clinically challenging. The clinical assessment is helped by standardised and validated scales targeted at the critically ill patient [1, 2, 3, 4]. A bad score on these scales implies severe brain damage and is a poor prognostic sign $[3,5,6,7,8]$. One problem in giving an accurate prognosis for an individual patient however is that some patients with a poor score make an unexpectedly good recovery, whilst others with a very good score suddenly deteriorate with subsequent poor outcome. The additional use of CSF biomarkers may help to improve the prognostic accuracy for an individual patient.

This review is aimed at those working with patients in neurocritical care, either in a clinical or research context. Firstly, some essential definitions are provided. Secondly, the anatomical and physiological basis for the release of biomarkers into the CSF is reviewed, including a synopsis of the function of the blood brain barrier (BBB). To illustrate the release of biomarkers from the cytosol of the damaged brain cells into the adjacent body fluid compartment, a video of an experimentally damaged neuron is shown. A list of potential biomarkers and those under current investigation is provided and the most important CSF biomarkers are discussed in detail. Finally, a summary of the evidence that CSF biomarkers improve prognostic accuracy is given, together with some recommendations for future biomarker research in neurocritical care.

\section{Definitions}

The definitions presented here were adapted and extended from the experience with biomarkers in oncology [9] and a recent workshop on biomarkers at the National Institutes of Health $(\mathrm{NIH})$ on multiple sclerosis [10].

- Biomarker: "a characteristic that is objectively measured and evaluated as an indicator of normal biologic processes, pathogenic processes, or pharmacological responses to therapeutic intervention." [10] Biomarker may be sub-classified into:

- Prognostic biomarkers: biomarkers which are associated with a clinical outcome, such as a time-to-event outcome [9].

- Predictive biomarkers: biomarkers which can narrow the choices between treatment options [9].

- Process biomarkers: biomarkers which allow monitoring of the dynamics and activity of pathological features.

- Safety biomarkers: biomarkers which allow evaluation of the safety of treatments and give an early warning of unwanted side-effects. 
- Surrogate endpoint: "defines a biomarker that is intended to serve as a substitute of a clinically meaningful endpoint and is expected to predict the effect of a therapeutic intervention or the evolution of disease. [10]"

- Clinical endpoint: "defines a meaningful measure which captures how a patient feels, functions or survives. [10]" Clinical endpoints may be subclassified into:

- Intermediate endpoint: represents "a clinical endpoint that is not the ultimate outcome but is nonetheless of real clinical usefulness. [10] " (e.g. the GCS or FOUR score)

- Ultimate clinical outcome: represents "a clinical endpoint reflective of accumulation of irreversible morbidity and survival. [10]"

- Time-to-event outcome: The time until a predefined event occurs, e.g. time to discontinuation of assisted ventilation, time to discharge from ITU or time to death.

In neurocritical care, where many patients are unresponsive or sedated, a biomarker provides additional information on damage to the brain parenchyma. It is my personal opinion that a CSF biomarker should always be regarded as an extension of the clinical assessment and judgement.

\section{Blood-brain barrier}

Any substances circulating in the bloodstream may be relatively harmless systemically, but could cause havoc by disturbing brain homoeostasis if they allowed into the ECF. For this reason the brain parenchyma is protected from the systemic circulation by the BBB. Some basic understanding of the BBB function is therefore necessary for the balanced interpretation of data on CSF biomarkers.

The blood-brain barrier (BBB) prevents the unselected diffusion of substances from the blood into the CSF (Figure 1 A). The blood-CSF barrier (BCB) in contrast is a filter which permits substances to diffuse from the blood into the CSF according to their molecular seize [11]. Strictly speaking one should separate between the BBB and BCB function, but for simplicity this is seldom done.

For assessment of the BBB/BCB function the current gold-standard is the measurement of albumin in the CSF (normal range 144-336 mg/L) ${ }^{1}$ and serum (normal range 28.4-53.8 g/L) [12]. Because albumin is not produced intrathecally, all CSF albumin must be derived from the blood by diffusion through the meninges [13]. An intact BBB/BCB will only allow a small amount of albumin to diffuse into the CSF. The normal quotient of CSF to serum albumin calculates

\footnotetext{
${ }^{1}$ Reference values are reflected by many pre-analytical and analytical factors. The reference values from one laboratory are not necessarily appropriate for another laboratory using different methods, or for another hospital providing a service to a different patient population.
} 


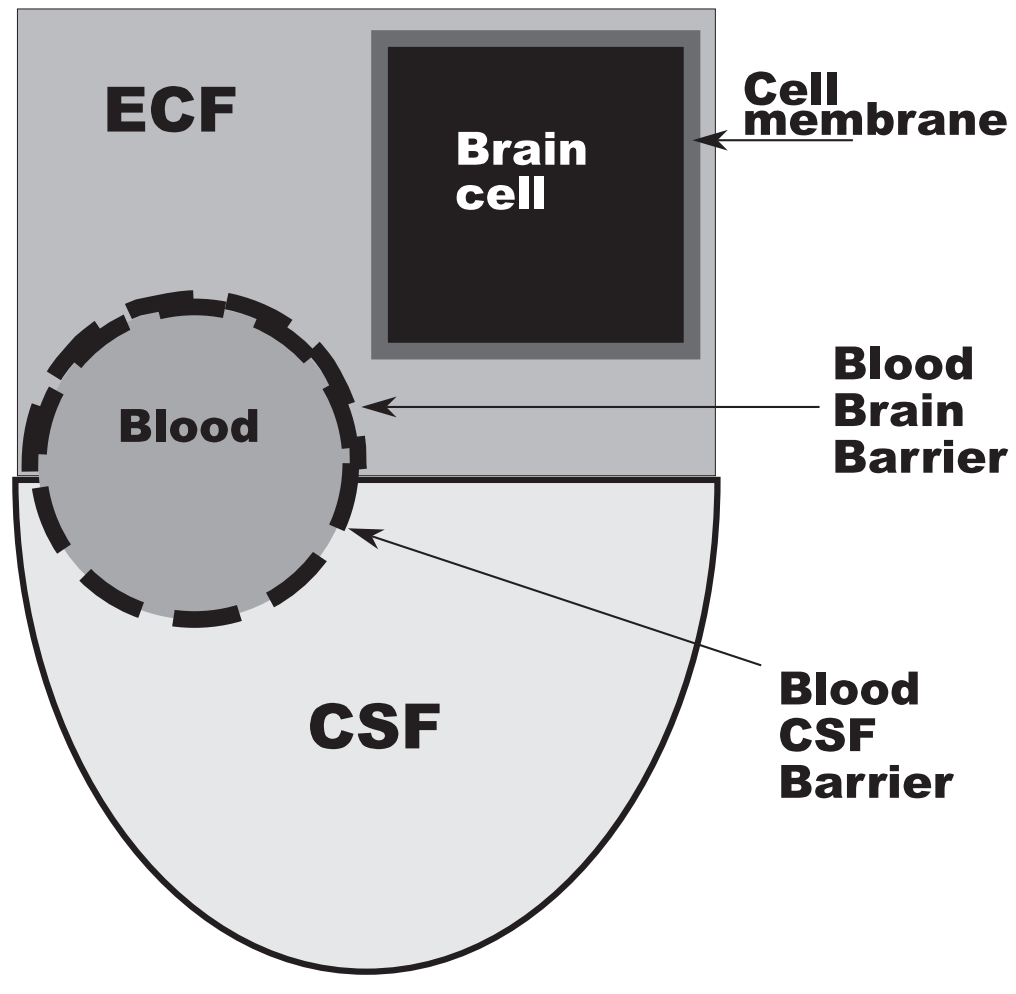

Figure 1: (A) A simplified diagram of the tight blood-brain barrier (BBB) which separates the blood from the extracellular fluid (ECF) of the brain parenchyma. The very tight cell membrane prevents proteins from the cytosol diffusing into the ECF. The less tight blood-CSF barrier (BCB) allows substances to diffuse from the blood into the CSF. 


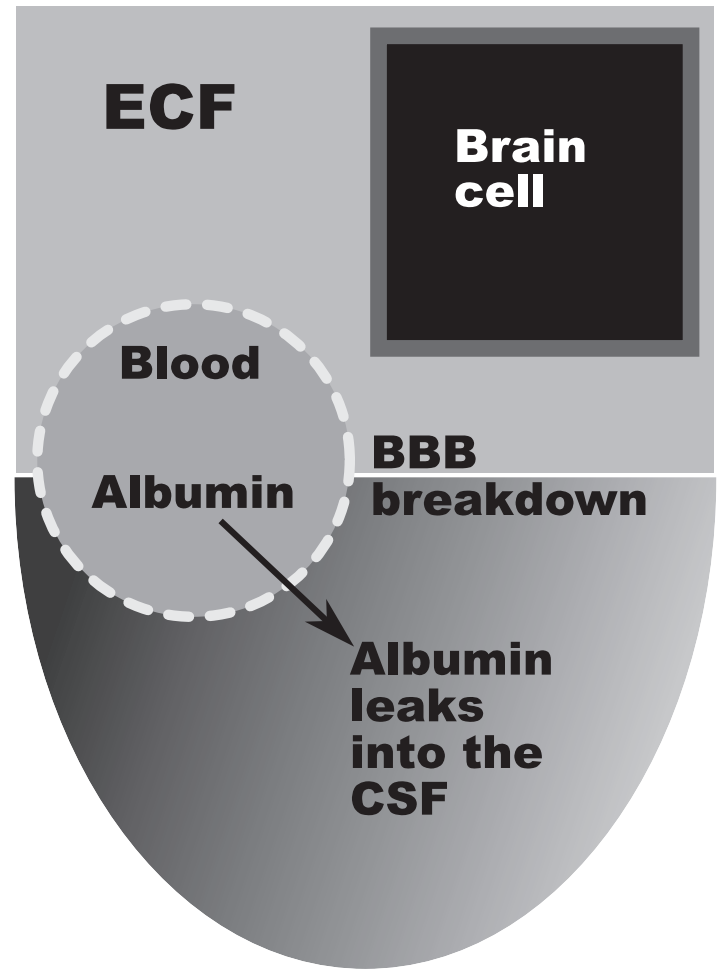

Figure 1: (B) Breakdown of the blood-CSF barrier results in leakage of albumin from the blood into the CSF. 


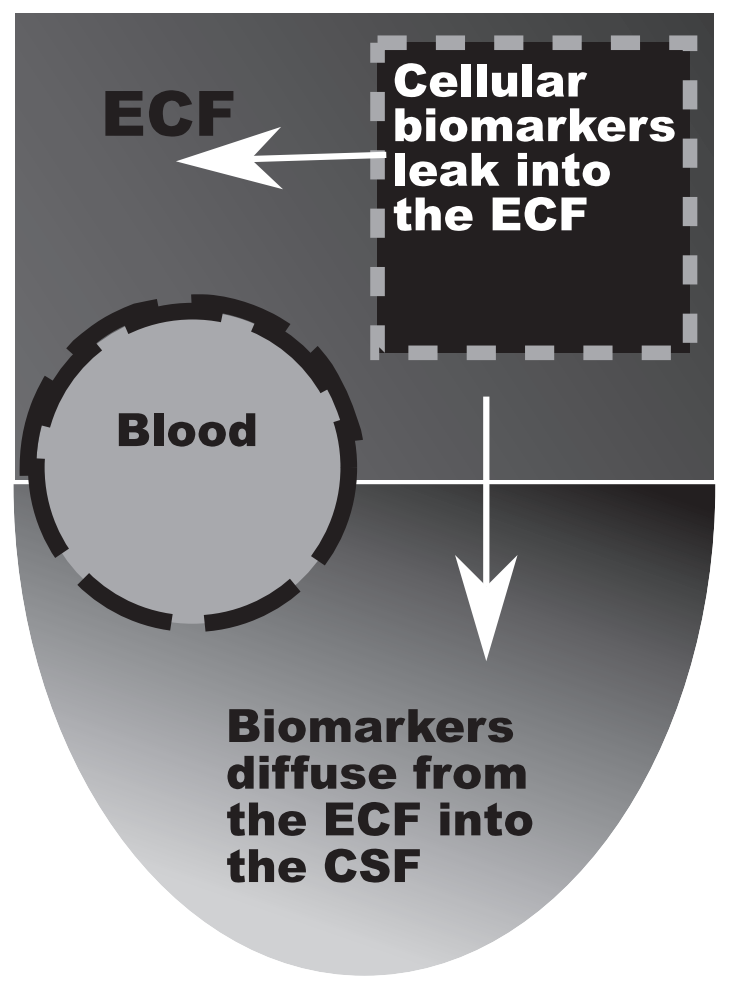

Figure 1: (C) Cellular death following brain damage leads to disintegration of the cellular membrane. Biomarkers leak from the cytoplasm into the adjacent ECF. From the ECF these biomarkers then equilibrate with the CSF. 


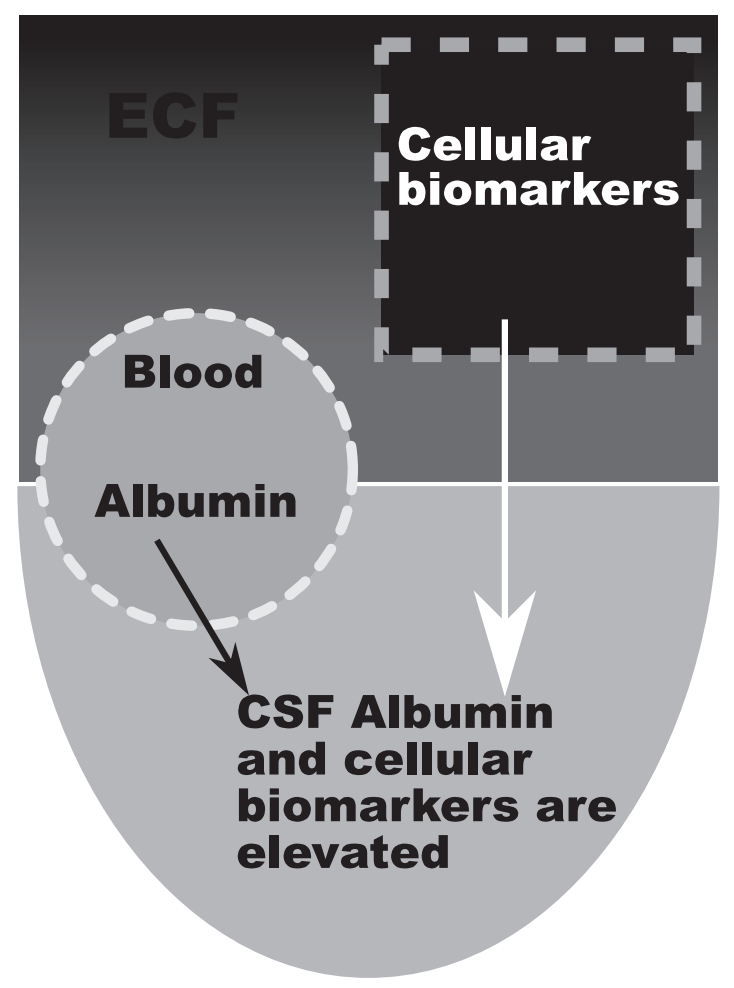

Figure 1: (D) Illustrates the situation when both the blood-CSF barrier and the cell integrity break down. Because of the leakage of fluid and proteins from the blood into the CSF one would expect a dilution effect, artificially lowering the CSF levels of biomarkers released from dying brain cells. 
to $0.0018-0.0074$ [12]. A breakdown of the BCB leads to leakage of serum albumin locally into the CSF (Figure $1 \mathrm{~B})^{2}$. Consequently the CSF albumin rises and therefore the CSF to serum albumin quotient increases. The quotient of the CSF to serum albumin provides a widely accepted tool to approximate the integrity of the BBB. A CSF to serum albumin quotient $>0.0075$ is abnormal ${ }^{3}$. Because the CSF is absorbed through the arachnoid villi (which have no barrier function) any substance present in the CSF will enter the blood. There is no known biomarker specific for the endothelial cells of the blood vessels in the brain. This is important to remember because the integrity of the BBB can only be tested by analysing both a blood and a CSF sample. Any conclusion about the integrity of the BBB based on an isolated blood sample is questionable.

Irreversible damage to the brain results from death, of a number of brain cells, either by necrosis or apoptosis causing the cellular membrane disintegrate (see video). This leads to leakage of biomarkers from the cytoplasm into the adjacent ECF (Figure $1 \mathrm{C}$ ). From the ECF these biomarkers diffuse into the CSF from where they can readily be sampled by lumbar puncture or via an extraventricular or a lumbar drain.

What happens if there is BBB breakdown and additional death of neurons? Figure $1 \mathrm{D}$ illustrates how albumin and other proteins leaking from the blood into the CSF dilute the CSF concentration of proteins derived purely from the brain parenchyma. This is important to note, because high CSF levels of a biomarker such as neurofilaments [15] (or S100B [16]) in the context of BBB disruption, for example would still be regarded as a valid measure of damage to the CNS.

\section{Cerebrospinal fluid}

Normal CSF is clear and colourless. It consists of $99 \%$ of water and has a much lower protein concentration $(\approx 350 \mathrm{mg} / \mathrm{L})^{4}$ than the serum $(70,000 \mathrm{mg} / \mathrm{L})$.

The concentration of a CSF biomarker depends on:

1. If derived from the CNS parenchyma:

- Intrathecal production

- Leakage into the ECF

- Diffusion into the CSF

2. If derived from the systemic circulation:

- Serum concentration

\footnotetext{
${ }^{2}$ Because there is currently no data on time matched ECF/CSF/blood albumin levels, the relationship of albumin levels to differential breakdown of the BBB and BCB is unknown.

${ }^{3}$ Thompson uses the "percentage albumin transfer" $\left(\frac{C S F_{A l b}}{\text { Serum }_{A l}} * 100\right.$ instead [14]. A percentage albumin transfer $>0.7 \%$ is indicative of leakage of albumin from the serum through a damage BBB.)

${ }^{4}$ Please note that this value refers to the CSF total protein concentration which is higher then the CSF albumin concentration of $144-336 \mathrm{mg} / \mathrm{L}$ mentioned above.
} 
- BBB integrity

- Hydrodynamic radius

About $70 \%$ of CSF is derived from the choroid plexus by filtration from the blood [17, 18]. The highest filtration rate $(\approx 40 \mathrm{~mL}$ per hour [19]) occurs naturally at night, in the recumbent position with increased hydrostatic pressure, which probably accounts for clinical symptoms such as headache and nausea suffered in the morning by patients with hydrocephalus. The remainder of the CSF comes from the ECF of the brain parenchyma and through the meninges and the blood-nerve barrier at level of the nerve roots. The CSF is modified on its passage from the ventricles to the lumbar sac and this is influenced by the CSF flow rate [20]. As a rule of thumb the concentration of proteins derived from the plasma is highest in the lumbar CSF and shows a rostro-caudal gradient, because of diffusion through the blood-nerve barrier along the length of the spinal cord.

Proteins derived from the brain parenchyma, called by some authors brainspecific proteins (BSP) or CNS-specific proteins, only make up about $10 \%$ of the total CSF protein content [11]. Concentrations of some of these BSPs are higher in the ventricular CSF and others higher in the lumbar CSF [13]. With the availability of microdialysis as a clinical and research tool it may be possible in future to obtain longitudinal (e.g. hourly) samples from the ECF and ventricular and lumbar CSF. Such samples would be extremely valuable for future CSF biomarker research.

\section{CSF Biomarkers}

Biomarkers can be put in to 6 broad categories, of which cell-type specific biomarkers are most relevant for prognosis in neurocritical care because they allow for a precise estimate of the amount of CNS tissue destruction.

1. CSF pigments

2. CSF metabolic biomarkers

3. CSF cell-type-specific biomarkers

4. CSF biomarkers for widespread CNS damage

5. CSF free-radicals and biomarkers of oxidative stress

6. CSF biomarkers for inflammatory/immunological processes

\subsection{Pigments}

The clear CSF changes colour with the addition of substances such as bilirubin (yellow) or haemoglobin (red) [21]. Spectrophotometry allows quantitative 
measurement of pigments in the CSF [22, 23]. Because of the continuous conversion of haemoglobin to bilirubin, one expects oxyhaemoglobin levels to decrease as bilirubin levels increase following e.g. a subarachnoid haermorrhage (SAH). A secondary increase in CSF oxyhaemoglobin suggestive of microrebleeds, was observed in SAH [24]. Micro-rebleeds may be too small to be visible on $\mathrm{CT}$, so the quantification of CSF pigments may allow investigation of the occurrence and prognostic implications of micro-rebleeds.

\subsection{Metabolic biomarkers}

These biomarkers represent the intermediate- and end-products of the metabolic pathways. A very small sample volume can rapidly be analysed. The basic metabolic pathways are shared by most cell types and are therefore good indicators of global impairment, but are not specific for any particular cell type or pathological process (see Table 1). CSF glucose and pyruvate are routinely measured. CSF lactate is also relevant in certain conditions. During ischaemia the cellular metabolism switches from the aerobic to the anaerobic pathway leading to an increase of lactate and decrease of pyruvate which indicates a lack of $\mathrm{O}_{2}$ supply. Metabolic biomarkers were also amongst the first to be investigated in the extracellular fluid (ECF) using microdialysis [25].

\subsection{Cell-type specific biomarkers}

Cell-type specific biomarkers are proteins, lipids or circulating nucleic acids exclusively expressed by a specific cell-type, for example, neurofilaments are only expressed in neurons and their axons [15]. This is illustrated by a video on the Journal's website.

Link out to the video clip about here]
Caption to the video clip to be shown on the Journal's website:
the video shows a dorsal root ganglion with its axon in a culture
dish located within a laser-dissection microscope. A laser beam
is directed to the cell membrane of the neuron. As the membrane
is cut open the content of the cytoplasm is released into the cul-
ture media. Next, the axon is severed by the laser beam. All the
substances released into the culture medium can potentially be
quantified and used as biomarkers.

In the brain, cell-type specific biomarkers are released into the extra-cellular fluid (ECF) following any form of cellular damage. From the ECF these biomarkers diffuse into the cerebrospinal fluid (CSF) and thence into the systemic circulation (Figure $1 \mathrm{C}$ ). Figure 2 illustrates how neurofilaments one(one example of a cell-type specific biomarker) are released. 


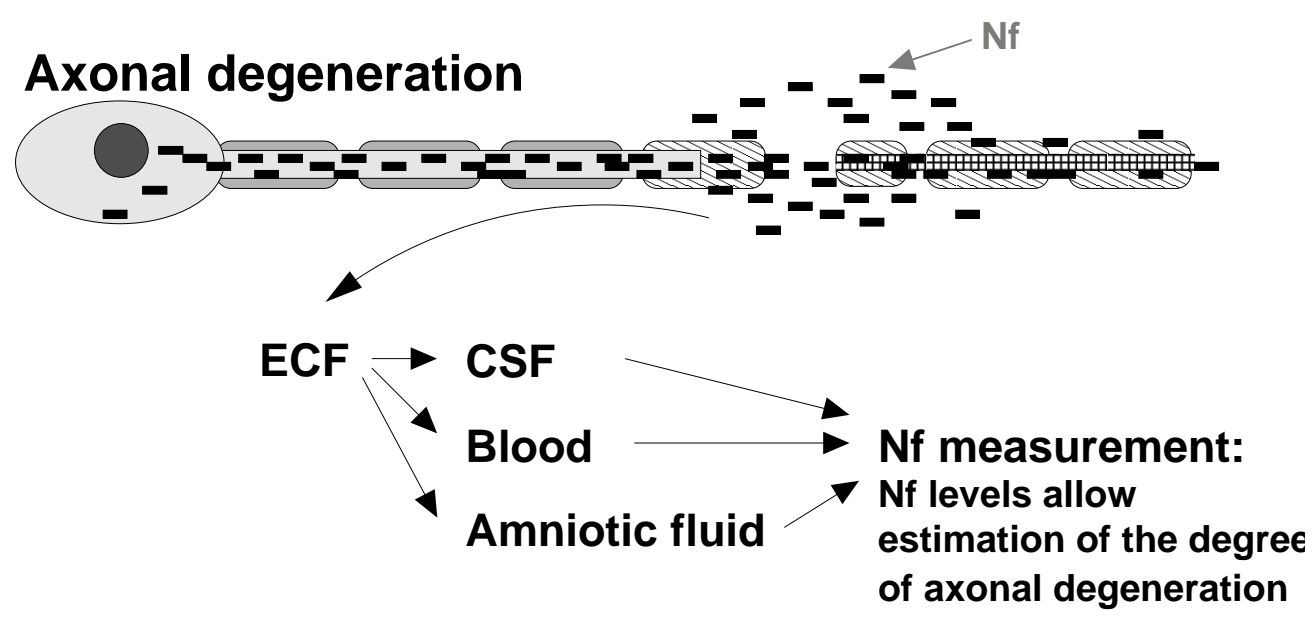

Figure 2: Neurofilaments are released into the extracellular fluid (ECF) following axonal disintegration. From the ECF Nfs equilibrate with the adjacent body fluid compartment. Quantification of Nfs is therefore possible from the cerebrospinal fluid (CSF) [26, 27, 28], blood [29, 30] and amniotic fluid [31]. The degree of axonal degeneration is related to the amount of $\mathrm{Nf}$ measured in these body fluids. For this reason body fluid Nf levels permit estimation of the amount of axonal degeneration. Axonal degeneration is relevant because axonal loss is irreversible and a leading cause of persistent disability in an individual patient. 
A list of established and emerging CSF biomarkers is presented in Table 1. Only few are cell-type specific; most are indicative of more widespread damage to the CNS parenchyma. 
Table 1: Established and potential CSF biomarkers and their cellular sources for acute CNS damage, assuming a normal PNS.

\begin{tabular}{|c|c|c|c|c|c|c|}
\hline $\begin{array}{l}\text { CSF } \\
\text { Biomarker }\end{array}$ & $\begin{array}{l}\text { Neuron } \\
\& \text { Axon }\end{array}$ & $\begin{array}{l}\text { Astro- } \\
\text { cyte }\end{array}$ & $\begin{array}{c}\text { Micro- } \\
\text { glia }\end{array}$ & $\begin{array}{l}\text { Oligoden- } \\
\text { drocyte }\end{array}$ & $\begin{array}{l}\text { Choroid } \\
\text { plexus }\end{array}$ & Blood \\
\hline $14-3-3 \gamma$ & ++ & + & + & + & & + \\
\hline ABP & + & & & & & \\
\hline AD7c-NTP & + & & & & & \\
\hline Albumin & & & & & & + \\
\hline$\alpha$ spectrin & + & + & + & + & + & + \\
\hline$\alpha(1) \mathrm{BG}$ & & + & & & & \\
\hline$\alpha$-internexin & + & & & & & \\
\hline ApoE & & & + & & & + \\
\hline$\beta$-tubulin & + & & & & & \\
\hline$\beta$-2-Microglobulin & & & + & & & \\
\hline$\beta$-trace & & & & $(+)$ & $+{ }^{5}$ & \\
\hline Clusterin & + & + & & + & + & \\
\hline Cystatin C & + & & & & + & \\
\hline EDG-8 & & & & + & & \\
\hline FABPs & + & + & + & + & & + \\
\hline FFA & + & + & + & + & & + \\
\hline Ferritin & & & + & & & + \\
\hline GFAP & & + & & & & \\
\hline Glucose & + & + & + & + & & + \\
\hline Glutamate & + & + & + & + & & + \\
\hline HK6 & & & & & + & \\
\hline HNE & + & + & + & + & & + \\
\hline Hypocretin-1 & $+{ }^{6}$ & & & & & \\
\hline Isoprostanes & + & + & + & + & & + \\
\hline Lactate & + & + & + & + & & + \\
\hline MAG & & & & + & & \\
\hline MBP & & & & + & & \\
\hline MDA & + & + & + & + & & + \\
\hline MOBP & & & & + & & \\
\hline MOG & & & & + & & \\
\hline NAA & ++ & + & + & + & & \\
\hline NCAM & + & & & + & & \\
\hline NOx & + & + & + & & & + \\
\hline NSE & + & & & & & + \\
\hline Neurotrophins & + & + & + & + & & \\
\hline $\mathrm{Nf}$ & ++ & & & & & \\
\hline OMgp & & & & + & & \\
\hline PLP & & & & + & & \\
\hline
\end{tabular}

${ }^{5}$ mainly derived from meningeal cells

${ }^{6}$ from hypothalamic neurons 


\begin{tabular}{|c|c|c|c|c|c|}
\hline PrPc & + & & & & \\
\hline Pyruvate & + & + & + & + & + \\
\hline S100B & & ++ & & + & \\
\hline SFas (sCD95) & + & & & & \\
\hline Tau & + & + & + & + & \\
\hline Ubiquitin & + & + & + & + & + \\
\hline Vimentin & + & + & + & & \\
\hline
\end{tabular}

Neurofilaments Neurofilaments (Nf) are the key building blocks of the axonal cytoskeleton. The Nf protein is a heteropolymer composed of four subunits: a light (NfL), a medium (NfM), and a heavy ( $\mathrm{NfH}$ ) chain [32], and $\alpha$-internexin $[33,34,35]$. $\mathrm{Nf}$ are almost exclusively expressed in neurons and axons [27, 15]. Following damage to the neuron and/or axon, the cytoplasmatic contents are released into the extracellular fluid (ECF) (Figure 2 and video). From the ECF $\mathrm{Nf}$ diffuse into other body fluid compartments including the cerebrospinal fluid (CSF) (Figure $1 \mathrm{C}$ ).

High-throughput analysis of Nfs is possible using enzyme-linked immune assays (ELISA). In-house ELISAs have been developed for $\mathrm{NfL}$ and $\mathrm{NfH}$ [26, $27,28,30]$. These assays are robust and have been cross-validated [36, 37]. A commercial ELISA kit for quantification of the phosphorylated $\mathrm{Nf}$ heavy chain (pNfH) has recently become available (Chemicon, catalogue number NS170).

CSF Nf levels have been studied most extensively in patients suffering from a SAH, all studies revealing comparable results [27, 38, 36, 39, 40]. Following the bleed, CSF NfH and NfL levels are considerably elevated in all SAH patients when compared to controls. One longitudinal UK study suggested that there may be a secondary increase of CSF NfH levels [38]. This was confirmed in a subsequent longitudinal US study and interpreted as the consequence of secondary brain damage caused by delayed cerebral ischaemia. The study also demonstrated that patients with a poor outcome on the 6-month GOS (1 to 3) showed a secondary increase of ventricular CSF NfH levels about four days after the bleed [39]. Nylén et al. went on to show in a cross-sectional study that lumbar CSF NfL levels 10-14 days after the bleed were significantly higher in those patients with a bad recovery (GOSE 1 to 4) compared to those with a favourable outcome (GOSE 5 to 8) [40]. CSF NfH and NfL levels correlated with the initial severity of the injury $[39,40]$.

Norgren et al. showed that CSF NfL levels were elevated in $5 / 6$ patients with stroke [28]. In a longitudinal study on 34 patients with a minor stroke, we found a weak correlation between $\mathrm{CSF} \mathrm{NfH}$ levels and the modified Rankin score at discharge (unpublished data).

Rosén et al. showed that CSF NfL levels taken an average of 17.5 days after cardiac arrest predicted the one-year outcome on three scales: GOS, minimental state examination (MMSE) and activity of daily living (ADL) [41]. In this particular study the scoring on the GOS was inverse to convention [2, 42], thus explaining the positive correlation of the CSF NfL levels with the GOS $(\mathrm{R}=0.79)$ rather than the expected negative correlation [41]. 
Glial fibrillary acidic protein Glial fibrillary acidic protein (GFAP) is a key building block of the cytoskeleton of the astrocyte. During astrocytosis this cytoskeleton rapidly reshapes and the tightly packed GFAP polymer loosens up within minutes, thus exposing more epitopes for recognition by anti-GFAP antibodies. This explains the extensive immunohistochemical staining with antiGFAP antibodies of astrocytosis. Importantly, astrocytes are particularly vulnerable to ischaemia $[43,44,45]$ and the measurement of GFAP released during astrocytosis and astroglial disintegration provides a tool for monitoring glial pathology.

A number of in-house GFAP ELISAs have been developed [46, 47, 48, 49, 50] and a commercial kit is available through Biovendor (Heidelberg, Germany, Cat No. RD 192072200).

Nylen et al. found that CSF GFAP levels were elevated in patients with vasculitis [51]. Inspection of Table 2 in reference [51] suggests that CSF GFAP levels are particularly high in patients with systemic lupus erythematosus (SLE) who also presented with focal neurology.

Gurnett et al. found levels of CSF GFAP (but not CSF NSE) to be increased in children following an epileptic seizure. CSF GFAP levels were highest in children with symptomatic epilepsy and prolonged seizures [52].

CSF levels of GFAP were found to be elevated in patients with SAH [53]. A subsequent longitudinal study showed CSF GFAP levels to be pathological in $93 \%$ of all samples [54]. By comparing non-survivors with survivors, significantly higher CSF GFAP levels were found for the former on day 2 and again on days 6 and 7 following the bleed. A simple model for the interpretation of CSF GFAP levels in patients with SAH was proposed based on these results (Figure 3). Given the number on studies on serum GFAP levels in patients with SAH and stroke $[55,55,56,57,58]$ there is a lack of data on CSF GFAP.

Myelin proteins Myelin proteins specific for the CNS and PNS consist of several hydrophobic proteins. Myelin-associated glycoprotein (MAG, $\approx 100 \mathrm{kDa}$ ) is expressed both in the CNS and PNS and accounts for about $0.1-1 \%$ of total myelin protein [59]. Due to alternative mRNA splicing, two MAG isoforms (LMAG, S-MAG) exist. Myelin-associated oligodendrocytic protein (MOBP) is a small protein present only in oligodendrocytes. Myelin basic protein (MBP) is expressed in the CNS and PNS in a variety of isoforms due to alternative splicing and an even larger number of post-translational modifications. Myelin/oligodendrocyte glycoprotein (MOG) is a transmembrane protein in the CNS. Oligodendrocyte/myelin glycoprotein (OMgp) is a $120 \mathrm{kDa}$ glycosylated extracellular molecule in the CNS. The proteolipid protein belongs to the tetraspanins and is one of the most hydrophobic proteins known [59]. Of all these myelin proteins, it is mainly myelin basic protein (MBP) which has been measured in the CSF.

Myelin basic protein (MBP) Myelin basic protein (MBP) is encoded on chromosome 18q23 and has 170 amino acid residues and a molecular weight of 


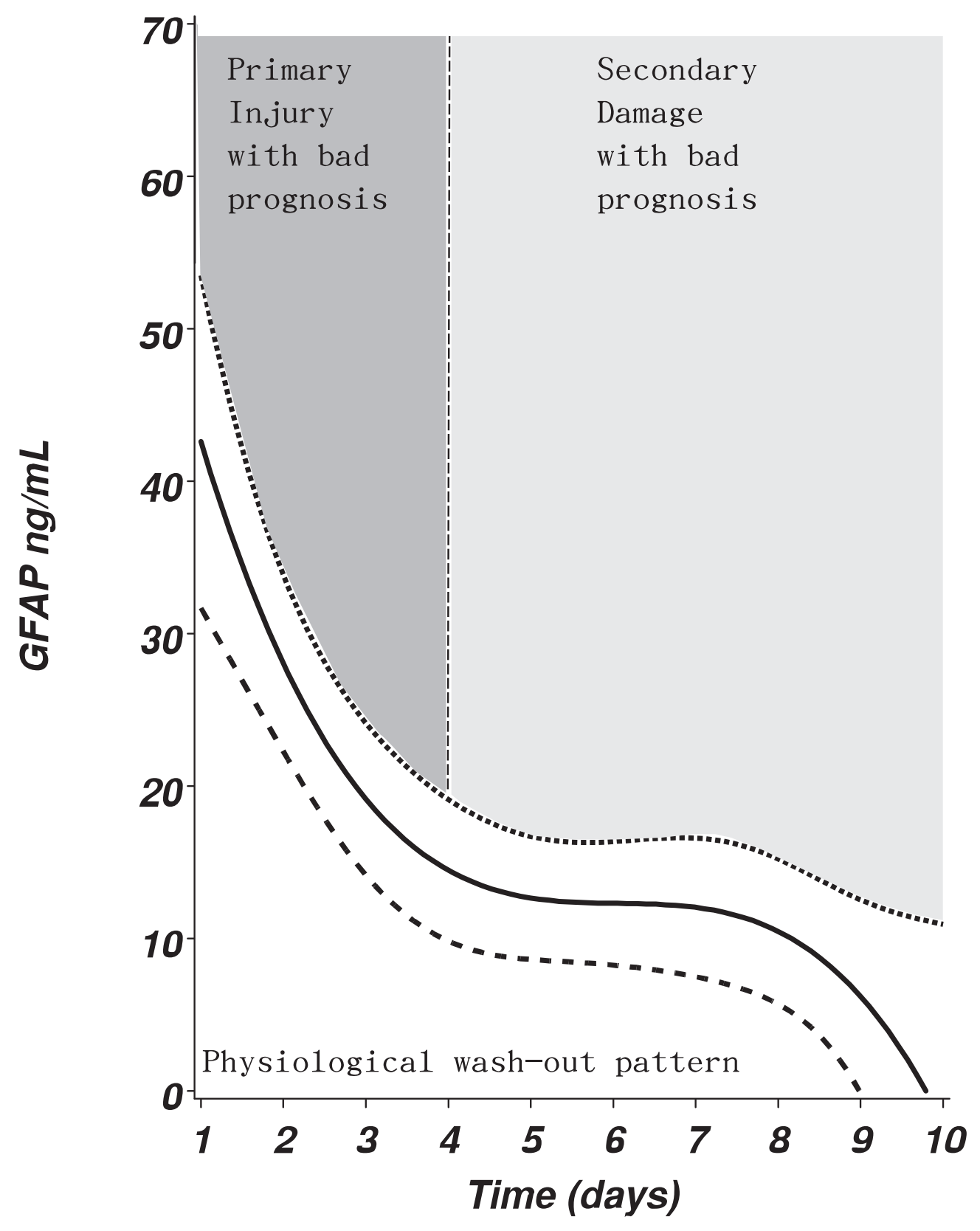

Figure 3: A model how longitudinal CSF GFAP levels may help improving the prognostic accuracy in patients with SAH. CSF GFAP levels within the darkgrey area are suggestive of a bad prognosis based on the severity of the primary brain injury, whilst levels in the light-grey area suggest poor prognosis due to secondary brain damage. (Figure reprinted with permission from reference [53] ) 
$18,500 \mathrm{Da}$. MBP is a major constituent of the myelin sheath of oligodendrocytes and Schwann cells. MBP-related transcripts are also present in the bone marrow and immune system, arising from "Golli-MBP" with 3 additional exons located upstream to the classical MBP.

Due to its basic properties the quantification of MBP is challenging. Numerous research groups have developed in-house methods and a range of commercial assays are available.

CSF MBP has been measured in patients with $\operatorname{TBI}[60,61,62,63]$, hydrocephalus [64, 65, 66, 67], SAH [68], brain tumours and metastatic brain disease [69, 70, 71], asphyxia in children [72, 73], following chemotherapy $[74,75,76,77]$, stroke $[62,70,78,79,80]$, encephalitis [70, 81, 82, 83, 80, 73], epilepsy [66], and following neurosurgery in patients with TBI and tumours [84]. MBP has probably been investigated most intensively in the CSF of patients suffering from multiple sclerosis (for review see reference [85]).

Noseworthy et al. were the first to describe a relationship between CSF MBP levels and outcome (GOS at 7 days, 3 months and 6 months) in patients with severe closed head injury [63]. In patients with SAH, CSF MBP levels were related to the occurrence of vasospasm-related delayed ischaemic neuronal deficit (DIND), infarct size and the 3 months GOS in one study [68]. In stroke CSF, MBP levels were related to the short-term outcome [78]. In asphyxiated full-term infants, increased CSF MBP levels were related to poor outcome (death or cerebral palsy at one year) [72]. In children with hydrocephalus and seizures, Levin et al. did not find CSF MBP levels to be of prognostic value [66].

Circulating nucleic acids Following cellular disintegration by apoptosis or necrosis, DNA and RNA are released into the blood [86]. Some cells may even to actively secrete DNA. Several methodological issues still need addressing, but oncology and neonatal medicine already use circulating nucleic acids for diagnostic and monitoring purposes [87]. Lam et al. investigated circulating nucleic acids in 44 patients suffering from stroke and found them to be a better predictor of outcome than S100B on the 6 months modified Rankin scale [88]. Circulating nucleic acids specific for different cell types could become an interesting future CSF biomarker.

\subsection{CNS specific biomarkers}

There are a number of CSF biomarkers in Table 1 which are not exclusively expressed by one single cell-type, but are nevertheless valuable in the assessment of damage to the CNS. Some of these may even be present in the serum due to systemic release, but if measured from the CSF they still allow for estimation of CNS damage.

Neuron specific enolase (NSE) Enolase is one of many glycolytic enzymes and consists of three subunits $(\alpha, \beta$ and $\gamma)$ [89]. In the CNS the $\alpha \gamma$ and $\gamma \gamma$ 
isoforms are mainly localised within the neurons and therefore called neuronspecific enolase (NSE) [90]. Generally, NSE levels are now mainly used as a tumour marker for lung cancer [91].

Earlier studies on CSF NSE levels found them to be elevated in patients with acute encephalitis, meningitis, CVA, acute polyradiculoneuritis and brain tumours (see Figure 2 in reference [92]). This findings were later confirmed and the list extended to brain tumour and epilepsy [93]. This makes CSF NSE levels important in neurcritical care.

Some authors found CSF NSE to be increased in children and adults following an epileptic seizure, particularly after a prolonged seizure [94, 95, 96], but others did not $[52,97,98]$. Comparing CSF and serum NSE levels in a heterogeneous group of patients with meningitis, acute brain injury with impaired levels of consciousness, neurocysticerosis and normal controls, Lima et al. found the former to be related to the GOS at discharge or death [99]. In one study of patients with GBS, high CSF NSE values predicted a longer disease duration [100]. Following cardiac arrest, elevated CSF NSE levels found 72 hours after the event were related to functional outcome [101].

Pleines et al. showed CSF NSE levels to be considerably elevated in TBI patients for the first 3 days following the event and they slowly decreased over the next 2 weeks [102]. The mean CSF NSE levels correlated with the contusion size on CT, but did not correlate with outcome on the GOS [102]. Similarly Ross et al. did not find CSF NSE levels to correlate with the GOS, APACHE II or ISS [103].

CSF NSE levels were also markedly elevated in children with TBI compared to controls [104]. A secondary increase of CSF NSE levels was observed in 4 of 5 children with inflicted TBI (iTBI) (see Figure 2 in reference [104]). The authors note that $\mathrm{ITBI}$ in children is frequently associated with violent shaking and/or impact with a hard surface, in addition to delayed presentation to health care professionals, potentially leading to hypoxia and ischaemia. This leads to the suggestion that delayed neuronal death may be an important feature in iTBI [104]. This observation is consistent with an earlier study in asphyxiated infants which correlated elevated CSF NSE levels with outcome (death or cerebral palsy at 1 year) [72]. The Pittsburgh group then went on to investigate the prognostic value and found CSF NSE levels to correlate with the 6-months GOS [105]. However, their subgroup analysis showed that this was only the case in children over the age of four [105].

S100B Originally isolated from the bovine CNS by Moore in 1965 [106], the protein was named $\mathrm{S} 100$ because of its solubility in $100 \%$ saturated ammonium sulphate at neutral $\mathrm{pH}$. S100B is now known to belong to a large family of $\mathrm{S} 100$ proteins [107]. S100B is coded on chromosome 21q22.3 [108] and consists of 91 amino acids and its molecular weight corresponds to $10-12 \mathrm{kDa}$. S100B is a water-soluble, cytoplasmic protein and contains $2 \mathrm{EF}$-hand calcium-binding domains $\left(4 \mathrm{Ca}^{2+}\right.$ per dimer). The $\mathrm{S} 100$ proteins also bind $\mathrm{Zn}^{2+}$ and $\mathrm{Cu}^{2+}$ [109]. 
For quantification of S100B there are a number of in-house developed ELISAs [110, 92, 111, 112, 80] and a range of commercially available ELISAs such as the Can Ag S100 EIA (Can Ag Diagnostics AB, Gothenburg, Sweden), the ELISA NEXUS CX ${ }^{\mathrm{TM}}$ S100 (Syn X Pharma INc., York, UK) and the Sangtec $\AA 100$ IRMA, Liaison $\AA$ Sangtec 100 and Sangtec 100 ELISA from DiaSorin AB (Bromma, Sweden) [113]. S100B levels are probably now most frequently used as a tumour marker for malignant melanoma [114, 115].

Earlier work on the CSF by Michetti et al. showed that S100B levels were elevated in patients with acute MS, acute encephalomyelitis, compression of the spinal cord and intracranial tumours [112]. The results were comparable to the observations by Sindic et al. who additionally found elevated CSF S100B levels in patients with stroke and SAH [111]. The spectrum of neurological diseases with elevated CSF S100B levels was broadened by Mokuno et al. to include patients with acute encephalitis, meningitis, SAH, CVA, multi-infarct dementia, Parkinson's disease, oral dyskinesias, cervical spondylosis, acute multiple sclerosis, acute and chronic polyradiculoneuritis and brain tumours (see Figure 2 in reference [92]). The findings in CVA were consistent with a later study [80]. Epilepsy has also been added to the list of acute neurological disorders with elevated CSF S100B levels [80, 116].

Over the last decade, a large number of studies has been published on serum S100B levels, mostly using the Sangtec $\AA$ ) 100 IRMA (for reviews see $[117,16,118,119])$. Less data is available on CSF S100B levels which, as one study showed, did not correlate with those found in the serum [120]. The original work by Sindic et al. included a small number of patients with clinical follow-up data and longitudinal CSF S100B levels suggesting that in herpes encephalitis and transverse myelitis high CSF S100B levels may be a poor prognostic sign (Table 2 in reference [111]).

Pleines et al. showed that CSF S100B levels were considerably elevated in TBI patients for the first 3 days following the event and they then slowly decreased over the next 2 weeks [102]. CSF S100B but not CSF NSE levels correlated with the contusion lesion size on CT and the GOS. Kay et al. showed elevated CSF S100B levels in TBI, but there was no correlation with outcome data $[121,122]$. Hayakata et al. showed CSF S100B levels to be elevated in severe TBI $(G C S<8)$ and particularly in those with high ICPs [123]. Peak CSF S100B level were strongly correlated with the ICP. Importantly CSF S100B levels were higher in patients with unfavourable outcome compared to those with favourable outcome [123]. In children with iTBI CSF S100B levels correlated with the 6-months GOS [105].

High CSF S100B levels were described in patients with SAH [120]. In another study on SAH, CSF S100B levels on admission were also elevated but did not correlate with either injury severity (GCS) or outcome (GOS) [124]. Analysing the longitudinal profile of the same cohort, Kay et al. showed that the peak CSF S100B levels over a 7-day observation period correlated with the 3-month GOS [125]. 
Tau This microtubule-associated protein tau, also known as neurofibrillary tangle protein and paired helical filament-tau (PHF-tau). Tau is encoded on chromosome 17 and due to alternative splicing of the mRNA, six isoforms with a molecular weight of 48 to $68 \mathrm{kDa}$ [126] exist in the human brain. Tau promotes microtubule stability and is used as a biomarker for neuro-axonal degeneration.

For quantification of tau most laboratories now use the hTau ELISA from Innogenetics (Ghent, Belgium).

Vandermeeren et al. were the first to report elevated CSF hTau levels in 5/11 patients with GBS [127]. Jin et al. then reported CSF hTau levels to be higher in patients with poor outcome (Hughe's functional grading scale score 2-5) compared to those with good outcome at 6 months [128]. Both studies contrasted with a small study by Süssmuth et al., who found CSF hTau levels to be normal in GBS $(n=5)$ [129]. All three groups used the same hTau ELISA from Innogenetics [127, 128, 129], suggesting that the different results may have been due to pre-analytical and clinical. Inspection of Figure 1 in reference [128] shows a bimodal distribution of CSF hTau levels for those patients with good outcome and it would be interesting to know from all the studies whether those patients with low CSF hTau levels had predominantly demyelinating pathology on electrophsysiological studies. Additionally, distal versus proximal axonal damage may account for the discrepancy [130]. Ost et al. found CSF tau levels to correlate with the 1-year outcome following TBI on the GOS, NIHSS and the Barthel daily living index [131].

Zemlan et al. developed antibodies directed against 30 to $50 \mathrm{kDa}$ cleaved tau (c-tau) [132]. They showed that the antibodies (ctau7, cTau8, cTau12) bind to the interior portion (Pro ${ }^{251}-\mathrm{MET}^{419}$ ) of the tau sequence with the $\mathrm{N}$ - and $\mathrm{C}-$ terminal amino acids being cleaved. The highest CSF tau levels were observed in patients with TBI when compared to MS, NPH or non-neurological controls [132]. Subsequently the authors measured CSF c-tau in patients with TBI, neurological- and non-neurological controls [133]. Initial c-tau levels were about 40,000-fold higher in the CSF of patients with TBI compared to either control group. C-tau and the GCS were independent predictors of the clinical outcome (GOS on discharge). The sensitivity/specificity limits for predicting an unfavourable outcome were $92 \% / 94 \%$ for c-tau and $50 \% / 100 \%$ for the GCS [133]. Quantification of C-tau opens an interesting future possiblity for CSF biomarker studies.

Amyloid beta peptide (ABP) The $\approx 700$ amino acid large amyloid precursor protein (APP) is cleaved at the $\beta$ and $\gamma$ sites by secretases into amyloid $\beta$ sequences of $40 / 43$ residues (ABP). The numbers behind the ABP refer to the cleavage site of the protein fragment (e.g. ABP 1-42). The amyloid beta peptide (ABP) is important in the pathogenesis of Alzheimer's disease. Nicoll et al. suggested a link between ABP deposition in the brain of patients with head injury and presence of the APOE epsilon4 allele [134]. In the CSF decreased levels of $A B P$ 1-42 provide valuable information for the differential diagnosis of neu- 
rodegenerative dementias [135]. CSF ABP has also been measured in patients with ischaemic stroke [136], SAH [125, 124], TBI [121, 122, 137, 138, 139] and acute bacterial meningitis [140].

In SAH both the CSF ABP 1-40 and 1-42 fraction were lower compared with CSF ABP levels in controls $[125,124]$. The maximum decrease in the CSF ABP concentration correlated with the 3 -months outcome in a longitudinal study [124].

In TBI, Kay et al. described the CSF ABP 1-40 and 1-42 as remaining low for at least 5 days following the injury [122]. There was no relationship with the GOS. In contrast, Franz et al. who found CSF ABP 1-42 levels to distinguish between good (GOS 4-5) and bad (GOS 1-3) outcome with a sensitivity of $100 \%$ and a specificity of $82 \%$ [138]. In a subsequent scientific exchange, Blennow and Nellgård make the important point that CSF ABP levels are about 5-fold higher in lumbar compared to ventricular CSF in patients with Alzheimer's disease [141]. In their reply, Franz et al. confirmed this point for their TBI cohort, showing about 2-fold higher ABP 1-42 levels in the lumbar compared to the ventricular CSF though the latter group had a worse outcome, potentially introducing a sample bias. All three studies [122, 138, 141] contrast with an earlier report on showing an increase of CSF ABP 1-42 levels in TBI patients [142].

Apolipoprotein E Polymorphism of the apolipoproteins E gene (APOE) influences the risk of the development of the sporadic from of Alzheimer's disease (AD) and is a risk factor for more severe disease in almost every neurological disorder except GBS [143, 144, 145]. In patients suffering from a head injury, Teasdale et al. was first to show that the presence of the APOE $\epsilon 4$ allele was associated with a significantly higher risk of mortality [146].

In the CNS ApoE is relevant for transport of cholesterol and lipids [147]. In TBI a decrease in CSF apoE levels was observed [121, 122], but CSF apoE levels did not correlate with the GOS [122]. Following SAH CSF apoE levels were also reduced, albeit to a lesser degree than in TBI [124, 125], and correlated with the 3-months GOS [125]. In ischaemic stroke CSF apoE levels were no different from the control group [136].

Hypocretin-1 Hypocretin-1 (synonymous orexin-A) is a neurotransmitter released from the posterior hypothalamus, and is relevant to the modulation of various different psychological functions $[148,149]$. Since Lin et al. recognised that CSF hypocretin-1 levels were decreased in the CSF of patients with narcolepsy, this small peptide has been studied in a large range of neurological conditions (for a review see [150]). Rejdak et al. showed in a longitudinal study that CSF hypocretin-1 levels were decreased in patients with acute brain injury (TBI and SAH) and remained undetectable in two patients with a destructive lesion of the thalamus/midbrain [151]. Because excessive fatigue or daytime sleepiness has been reported following a SAH [152], the authors suggested that a deficient hypocretin/orexin system may in part have been responsible for abnormalities in the sleep-wake cycle following acute brain injury. The findings 
were consistent with those of a larger cross-sectional study on patients suffering from TBI [153]. Another small longitudinal study on SAH patients $(n=15)$ confirmed that CSF hypocretin-1 levels decreased after SAH and were undetectable in those with a GCS of less than 8 on admission [154]. This was in line with a further study on 15 patients with $\mathrm{SAH}$, with a secondary decrease and particular low CSF hypocretin-1 levels in those who developed delayed ischaemic neuronal deficit (DIND) [155]. In 4/6 patients suffering from a paraneoplastic encephalitis (positive for anti-MA antibodies) and one patient with Hashimoto's encephalopathy, excessive daytime sleepiness was also associated with undetectable CSF hypocretin-1 levels $[156,157]$. Remarkably, the diurnal variation of CSF hypocretin-1 levels (about $4 \%$ ) has been described in healthy controls, suggesting that sampling time is of minor importance [158].

Alpha spectrin Two independent studies demonstrated that CSF Alpha-II spectrin levels were elevated in patients with severe TBI (GCS $<8)[159,160]$. The longitudinal data analysis of the study by Cardali and Maugeri showed that those patients who maintained high CSF levels of alpha-II spectrin and spectrin breakdown products (SBDPs) had a poorer outcome on the 6-months GOS [159]. In an experimental rat ischaemia model CSF $\alpha$-spectrin cleavage products were also detectable [161]. These authors point out the widespread distribution of $\alpha$-spectrin in essentially all non-neuronal cells [162] makes it unlikely that CSF $\alpha$-spectrin will ever become a specific biomarker for brain injury [161]. Nevertheless Pineda et al. demonstrated a differential time profile for calpain and caspase-3 mediated SBDPs [163]. In their study SBDPs were related to the 6 months GOS.

Cytochrome C Cytochrome $\mathrm{C}$ has been used as a biomarker for apoptosis. Statchell et al. showed CSF cytochrome $\mathrm{C}$ levels to be increased in children with iTBI compared to controls [164].

Taurine The amino acid taurine is currently best known as an additive to energising drinks. Experimentally taurine was released during cellular oedema, e.g. from astrocytes, and possessed anti-oxidant properties. Seki et al. demonstrated that CSF taurine levels were marginally increased in the CSF of patients with TBI when compared to patients with normal pressure hydrocephalus [165]. In an experimental TBI model in rats, Stover et al. showed that CSF taurine levels were increased about 8 hours after the injury [166]. The same group described an increase of CSF taurine levels in patients with subdural or epidural haematomas, contusions and generalised brain oedema [167].

NT-proBNP N-terminal (NT)-pro brain natriuretic peptide BNP) was shown to be elevated in a longitudinal study on ventricular CSF from TBI patients, but CSF NG-proBNP levels were not correlated with the 3-months GOS [168]. 
Ubiquitin Majetschak et al. showed that CSF ubiquitin levels continued to rise until death in 3 TBI patients, but recovered in 3 survivors from TBI [169]. The substantiated their findings by an experimental TBi study in pigs, showing that the biological half life of ubiquitin was about 1.3 hours. Contamination of the CSF by erythrocytes and consequent lysis accounted for about $15 \%$ of the CSF ubiquitin levels [169].

14-3-3 The 14-3-3 proteins $(\approx 30 \mathrm{kDa})$ are highly homologous, dimeric proteins, expressed in almost all eukaryotic cells from yeast to humans [170]. In humans one separate gene encodes for each of the seven isoforms $(\beta, \gamma, \epsilon, \eta$, $\sigma, \tau, \zeta$ ) [171]. Five major isoforms are found in the CNS, named $\alpha$ to $\eta$. 14$3-3 \beta$ is phosphorylated to $14-3-3 \alpha$, and $14-3-3 \zeta$ is phosphorylated to $14-3-3 \delta$. 14-3-3 proteins are involved in the regulation of the cell-cycle, cell signalling, intracellular trafficking and shaping of the cytoskeleton [170, 172, 173]. Since Boston et al. first described the presence of 14-3-3 in the CSF [174], the 14$3-3 \gamma$ isoform has been most commonly used as a CSF biomarker. 14-3-3 $\gamma$ is expressed in neurons, astrocytes, oligodendrocytes, and microglia [175]. To the best of my knowledge attempts to develop an ELISA for quantification of 143-3 isoforms has so far not been successful. This may be due to the epitopes of the different isoforms being crypotogenic, and/or the difficulties in raising antibodies against such ubiquitous proteins. Most laboratories currently use immunoblotting techniques for detection of $14-3-3 \gamma$ as described elsewhere [176].

CSF $14-3-3 \gamma$ is most frequently used as a biomarker in the differential diagnosis of Creuzfeld-Jakob disease [177] but, as with all other proteins 14-3-3 $\gamma$ is essentially released following cellular damage. CSF 14-3-3 $\gamma$ has been reported in patients with GBS [178], Hashimoto's encephalopathy [179, 180], meningitis and encephalitis [181, 175], stroke-like episodes [175] and transverse myelitis [182].

Nestin Nestin belongs to the intermediate filaments and is found in CNS progenitor cells. One group found CSF nestin levels to be decreased following asphyxia [183].

Albumin Ischaemia-modified albumin has been found in the serum in patients with stroke $[184,185,186]$. It can also be detected virtually whenever a small amount of hypoxia (e.g. anaerobic metabolism) occurs, including physical exercise [187, 188]. Ischaemia-modified albumin has not yet been investigated in the CSF. As discussed further down the timing of sampling is important for interpretation of the data. 


\subsection{Oxidative stress and free radicals}

Oxidative stress occurs when the physiological balance between oxidants and antioxidants is shifted towards the former. The production of oxidants such as free radicals is increased in patients with ischaemic brain damage [189]. This increase of free radicals causes oxidative stress which compounds existing brain damage. Therefore biomarkers of oxidative stress have the potential to allow monitoring of secondary brain injury and may be relevant for prognosis. Following ischaemia some $\mathrm{Ca}^{2+}$-activated enzymes such as cyclo-oxygenase (COX) and phospholipase $\mathrm{A}_{2}$ produce oxygen free radicals, whilst others such as nitric oxide synthase (nNOS and iNOS) produce nitric oxide (NO). Iron is another important source of free radicals $(\mathrm{OH}$. via the Fenton reaction), particularly after haemorrhagic brain injury.

Nitric oxide (NO) The methodological challenge is that free radicals cannot readily be measured in vivo. The biological half-life of NO is less then $5 \mathrm{sec}-$ onds, therefore downstream metabolites need to be quantified instead. For example, the $\mathrm{NO}$ metabolites $\mathrm{NO}_{2}$ and $\mathrm{NO}_{3}$ (commonly denoted as $\mathrm{NOx}$ for NO metabolites) can be measured in the CSF using a high-throughput technique [190,191]. CSF NOx levels did distinguish survivors from non-survivors in one study [38]. For a comprehensive review on NO, the reader is referred to more substantial reviews [192, 193, 194].

Excitatory amino acids Excitatory acids such as glutamate are neurotoxic if released in excess. There is an excellent review by Meldrum and Garthwaite on glutamate exitotoxicity [195].

Palmer et al. found that CSF glutamate levels increased for 3 days following TBI. CSF glutamate levels were about $7 \mu \mathrm{M}$, which was considered to be sufficiently high to cause further excitotoxicity [196]. Elevated CSF glutamate concentrations were also found by Baker et al. in a separate longitudinal study on TBI. The results were consistent with those by Zhang et al. who found CSF glutamate (and aspartate) levels to be elevated in TBI compared to neurological control patients and to correlate with the 3-months GOS [197]. Another longitudinal study found that the highest CSF glutamate levels peaked about 48 hours after TBI [198]. The same group then went on to describe an increase of CSF glutamate levels in patients with subdural or epidural haematomas, contusions and generalised brain oedema [167]. CSF glutamate levels were also increased in children with TBI [199]. These findings are in line with those obtained for CSF glutamate in an experimental study on TBI in rats [166].

Lipid peroxidation For lipid peroxidation, the unstable aldehydes malondialdehyde (MDA) and 4-hydroxynonenal (HNE) have been measured alongside thiobarbituric acid-reactive substances (TBARs). MDA has been related with stroke size and outcome [200]. 
Free fatty acids (FFA) Elevated levels of FFAs have been found in the CSF of patients with stroke, TBI, SAH. CSF FFAs levels were related to injury severity and outcome (for review see reference [201]).

Isoprostanes Isoprostanes are non-enzymatically synthesised from polyunsaturated fatty acids such as e.g. arachidonic acid [202]. They are released in their free form by phospholipases [203]. Importantly isoprostanes are relatively stable $[203,204] . F_{2}$-isoprostanes appear to be more reliable biomarkers for lipid peroxidation than e.g. MDA. Importantly, they are not only a metabolic product, but also have important biological functions [203]. For example the $15-\mathrm{F}_{2 t}$-IsoP is an important vasoconstrictor, alongside $9-$ epi- $15-\mathrm{F}_{2 t}$-IsoP and 15-epi-15- $\mathrm{F}_{2 t}$-IsoP, with the $\mathrm{E}$-series probably being even more potent vasoconstrictors (e.g. 15- $E_{2 t}$-IsoP) [205]. CSF levels of F2-isoprostanes have recently been measured in patients with SAH [206]. Peak and mean CSF $\mathrm{F}_{2}$-isoprostane levels correlated strongly with poor outcome, although these correlations were less impressive for plasma F2-isoprostane levels [206]. In patients with severe TBI $(\mathrm{GCS}<8) \mathrm{CSF}$ F2-isoprostane levels peaked on day one after the injury and were significantly higher in males than females, suggesting that the degree of lipid peroxidation differs with gender in TBI [207]. In children suffering from severe TBI, CSF F2-isoprostane levels were higher compared to control CSF when [208]. Wagner et al. showed in a longitudinal study that CSF F2-isoprostane levels on day one correlated inversely with the 6 -months GOS in women suffering from TBI [209].

Fatty acid binding proteins (FABPs) These are $\approx 15 \mathrm{kDa}$ proteins important for the uptake, transport and metabolism of fatty acids. Initially isolated from the heart muscle (H-FABP), they were subsequently found in many other cells including the brain [210]. In fact, FABs are present in all cells utilising fatty acids. Because they are not cell-type specific, and because their small molecular size allows for easy passage into the CSF, elevated CSF levels may be artefactual due to systemic involvement [211]. However, two studies independently found serum FABPs to be better prognostic indicators than serum S100B in patients with stroke $[212,213]$.

\subsection{Inflammatory and immunological biomarker}

The brain is an immunoprivileged organ. Inflammatory processes in brain tissue are tightly controlled [214]. The spectrum of CSF biomarkers relevant to the inflammatory and immunological diseases of the CNS is far beyond the scope of this review. Widening the spectrum from neurocritical care to the general intensive care unit, such biomarkers may also help to identify those patients who may be at risk of developing secondary brain damage due to critical illness [215, 216, 217]. Most inflammatory and immunological CSF biomarkers are, according to the introductory definition, "process biomarkers". 


\section{The future of CSF biomarkers}

Proteomics 2D gel electrophoresis is a well established technique that allows for separation of proteins according to molecular mass and charge. With the advent of mass spectroscopy, 2D gel electrophoresis has been re-employed to identify potential new biomarkers. Conti et al. found the acute phase proteins alpha-1 antitrypsin, haptoglobin 1 alpha1, alpha2 and beta to be increased in the CSF following TBI [218]. Interestingly the carboxyl-terminal portion of fibrinogen beta was only elevated in the CSF of patients with TBI, suggesting increased fibrinolysis in these patients [218]. Gao et al. have recently confirmed the results by Conti et al. Acute phase proteins and haptoglobins were increased in the CSF of patients with nTBI [219]. The authors also found CSF levels of prostaglandin- $D(2)-$ synthetase and cystatin $C$ to be higher in patients with iTBI when compared to patients with nTBI [219].

Burgess et al. performed a comparative study on ante- and postmortem CSF in in comparison to CSF in order to identify putative new CSF candidate biomarkers indicative for brain cell death [220]. These authors compiled an impressive list of 299 potential CSF biomarkers [220]. In a cell-culture model Siman et al. described release of over 60 cytoskeletal proteins from neurons [161].

\section{Pitfalls}

A range of pre-analytical and analytical pitfalls deserve to be mentioned. The CSF sampling technique, transport, time to storage and storage conditions should be standardised. Ideally one would like to have three serial tubes of CSF with at least $3 \mathrm{~mL}$ collected in a polypropylene tube. The reason for this is that most proteins are charged negatively and would bind to the positively charged surface of polystyrene or glass tubes, potentially leading to artificially low CSF levels of the biomarker in question. Samples should be spun down and the supernatant stored at least at $-20^{\circ} \mathrm{C}$ within one hour of collection. Longer transport and sample handling times may cause degradation of the biomarker and cause artificial results. Needless to say, sample storage in multiple aliquots of a small volume (e.g. $500 \mu \mathrm{L}$ to $1 \mathrm{~mL}$ in e.g. $1.5 \mathrm{~mL}$ Eppendorf tubes) allows for easy future analysis of several biomarkers, including the sending out of samples to other laboratories and avoiding repeated freeze-thaw cycles.

There are some simple analytical facts which help to guide the analysis of data. For example, the intra-assay coefficient of variation $\left(\mathrm{CV}=\frac{S D}{m e a n} * 100\right)$ of a technique indicates the degree of variation which may occur between performance of the same assay on the same sample at different time-points. For routine laboratory work a CV of less than $10 \%$ is desirable. Many assays developed for research are still in their infancy and will not achieve this target. This may not be critical as long as one remembers that an assay with a CV of, say, $20 \%$ cannot reliably be used to detect a difference between two groups (or 
two subsequent samples) of, say, $4 \%$. As a rule of thumb, the CV of a method determines how much trust one puts into the statistical result on group differences. In order to make publications comparable it is desirable to have some basic information about the methods such as the detection limit, sensitivity, linear range, parallelism and stability of the biomarker. For example it should come as no surprise if levels of a biomarker that is stable for one month at $4{ }^{\circ} \mathrm{C}$ are higher in samples from a study group, compared to "historical samples" from a control group collected 5 years earlier. Well-defined upper reference values determined in a large reference cohort are helpful for future comparison as they act as a benchmark. All analysis should be performed with the analyst being blinded to all other information.

Most patients in neurocritical care will receive large quantities of intravascular fluids. Levesl of many biomarkers in the blood may be reduced simply because of an i.v. fluid-related dilution effect. In situations like this one can use an addiotional measure, e.g. the haemotocrit as guidance for data analysis.

Substantial suggestions for future biomarker studies have been made by McShane et al. (see Table 1 in reference [9]) and offer themselves for adaption to other medical subspecialties.

\section{Conclusion}

Table 2 summarises the CSF biomarkers which were related to outcome data and may therefore be of value for improving the prognostic accuracy in acute CNS disease. This list is small compared to Table 1 and the inclusion of $\alpha-$ spectrin may be debatable [161]. Biomarker stability, accuracy of the analytical technique employed, study design and the pitfalls discussed above all take their toll. Two studies compared the prognostic accuracy of a CSF biomarker with the GCS [1, 2] in TBI [133] or established neurophysiological criteria [221] in GBS [130]. Both found CSF biomarkers to give the most accurate prognosis $[133,130]$.

The challenge for future studies is to combine CSF biomarkers with solid outcome data. 
Table 2: Summary table for those CSF biomarkers which were related to clinical outcome scales and may be of help in improving the prognostic accuracy in acute CNS disorders.

\begin{tabular}{llll}
\hline CSF biomarker & Disease & Outcome measure & Reference \\
\hline$\alpha$-spectrin ${ }^{7}$ & TBI & GOS & {$[159,163]$} \\
ABP 1-42 & SAH & GOS & {$[124]$} \\
ABP 1-42 & TBI & GOS & {$[138]^{8}$} \\
ApoE & SAH & GOS & {$[125]$} \\
Circulating nucleic acids & stroke & modified Rankin & {$[88]$} \\
F2-isoprostanes & SAH & GOS & {$[206]$} \\
F2-isoprostanes & TBI & GOS & {$[209]$} \\
FFA & TBI, SAH, stroke & GOS & {$[201]$} \\
GFAP & SAH & Survival & {$[54]$} \\
Glutamate & TBI & GOS & {$[197]$} \\
MBP & SAH & GOS & {$[68]$} \\
MBP & Stroke & short term prognosis & {$[78]$} \\
MBP & TBI & GOS & {$[63]$} \\
NOx & TBI \& SAH & Survival & {$[38]$} \\
NSE & GBS & disease duration & {$[100]$} \\
NSE & cardiac arrest & functional outcome & {$[101]$} \\
NSE & iTBI & Survival, GOS & {$[72,105]$} \\
NfH & GBS & F-score, MRCS & {$[130]$} \\
NfH \& NfL & SAH & GOS & {$[39,40]$} \\
NfL & Cardiac arrest & GOS & {$[41]$} \\
S100B & SAH & GOS & {$[125]$} \\
S100B & TBI & GOS & {$[102,123]$} \\
S100B & iTBI & GOS & {$[105]$} \\
Tau & GBS & F-score & {$[128]$} \\
Tau & TBI & GOS & {$[133,131]$} \\
\hline
\end{tabular}

\section{Acknowledgements}

I apologise to all colleagues whose work has not been cited due to space limitations.

\footnotetext{
${ }^{7} \alpha$-spectrin is also expressed in non-neuronal cells [162].

${ }^{8}$ These results are not consistent with [122]

${ }^{9}$ No such correlations were found in studies on TBI in adults [102, 103].

${ }^{10}$ These results were not consistent with [121, 122].
} 


\section{References}

[1] G Teasdale and B Jennett. Assessment of coma and impaired consciousness A practical scale. Lancet, 13:81-84, 1974.

[2] B Jennett and $M$ Bond. Assessment of outcome after severe brain damage. A practical scale. Lancet, i:480-484, 1975.

[3] E.F. Wijdicks, W.R. Bamlet, B.V. Maramattom, E.M. Manno, and R.L. McClelland. Validation of a new coma scale: The FOUR score. Ann Neurol, 58:585-593, 2005.

[4] E.F. Wijdicks. Clinical Scales for Comatose Patients: The Glasgow Coma Scale in Historical Context and the New FOUR Score. Rev Neurol Dis, 3:109-17, 2006.

[5] S.C. Ducrocq, P.G. Meyer, G.A. Orliaguet, S. Blanot, A. Laurent-Vannier, D. Renier, and P.A. Carli. Epidemiology and early predictive factors of mortality and outcome in children with traumatic severe brain injury: experience of a French pediatric trauma center. Pediatr Crit Care Med, 7:461-407, 2006.

[6] C. Atzema, W.R. Mower, J.R. Hoffman, J.F. Holmes, A.J. Killian, and A.B. Wolfson. Prevalence and prognosis of traumatic intraventricular hemorrhage in patients with blunt head trauma. J Trauma, 60:1010-1007, 2006.

[7] C.Y. Chung, C.L. Chen, P.T. Cheng, L.C. See, S.F. Tang, and A.M. Wong. Critical score of Glasgow Coma Scale for pediatric traumatic brain injury. Pediatr Neurol, 34:379-387, 2006.

[8] H.C. Tien, J.R. Cunha, S.N. Wu, T. Chughtai, L.N. Tremblay, F.D. Brenneman, and S.B. Rizoli. Do trauma patients with a Glasgow Coma Scale score of 3 and bilateral fixed and dilated pupils have any chance of survival? J Trauma, 60:274-208, 2006.

[9] L.M. McShane, D.G. Altman, W. Sauerbrei, S.E. Taube, M. Gion, and G.M. Clark. REporting recommendations for tumor MARKer prognostic studies (REMARK). Breast Cancer Res Treat, 100:229-235, 2006.

[10] R. Martin, B. Bielekova, R. Hohlfeld, and U. Utz. Biomarkers in multiple sclerosis. Dis Markers, 22:183-105, 2006.

[11] K Felgenhauer and W Beuche, editors. Labordiagnostik neurologischer Erkrankungen. Thieme Verlag Stuttgart, New York, 1999.

[12] H. Reiber. The discrimination between different blood-CSF barrier dysfunctions and inflammatory reactions of the CNS by a recent evaluation graph for the protein profile of cerebrospinal fluid. J Neurol, 224:89-99, 1980. 
[13] H Reiber. Dynamics of brain-derived proteins in cerebrospinal fluid. Clin Chim Acta, 310:173-86, 2001.

[14] EJ Thompson. The CSF proteins: a biochemical approach. Elsevier, 1988.

[15] A Petzold. Neurofilament phosphoforms: surrogate markers for axonal injury, degeneration \& loss. J Neurol Sci, 233:183-198, 2005.

[16] A. Kleindienst and M. Ross Bullock. A critical analysis of the role of the neurotrophic protein S100B in acute brain injury. I Neurotrauma, 23:1185-1300, 2006.

[17] K Felgenhauer. Proteinsize and cerebrospinal fluid composition. Klinische Wochenschrift, 52:1158-1164, 1974.

[18] S.I. Rapoport. Neurobiology of cerebrospinal fluid, chapter Passage of proteins from blood to cerebrospinal fluid, pages 233-245. Plenum, New York, 1983.

[19] C. Nilsson, F. Stahlberg, C. Thomsen, O. Henriksen, M. Herning, and C. Owman. Circadian variation in human cerebrospinal fluid production measured by magnetic resonance imaging. Am J Physiol, 262:R20-4, 1992.

[20] H. Reiber. Flow rate of cerebrospinal fluid (CSF)-a concept common to normal blood-CSF barrier function and to dysfunction in neurological diseases. J Neurol Sci, 122:189-203, 1994.

[21] A Petzold, G Keir, and LT Sharpe. Spectrophotometry for xanthochromia. N Engl J Med, 351:1695-1696, 2004.

[22] A. Petzold, L.T. Sharpe, and G. Keir. Spectrophotometry for cerebrospinal fluid pigment analysis. Neurocrit Care, 4:153-62, 2006.

[23] UK NEQAS. National guidelines for analysis of cerebrospinal fluid for bilirubin in suspected subarachnoid haemorrhage. Ann Clin Biochem, 40:481-408, 2003.

[24] K Rejdak, A Petzold, MA Sharpe, et al. Cerebrospinal fluid nitrite/nitrate correlated with oxyhemoglobin and outcome in patients with subarachnoid hemorrhage. J Neurol Sci, 219:71-6, 2004.

[25] M.M. Tisdall and M. Smith. Cerebral microdialysis: research technique or clinical tool. Br J Anaesth, 97:18-25, 2006.

[26] LE Rosengren, JE Karlsson, JO Karlsson, LI Persson, and C Wikkelso. Patients with amyotrophic lateral sclerosis and other neurodegenerative diseases have increased levels of neurofilament protein in CSF. J Neurochem, 67:2013-2018, 1996. 
[27] A Petzold, G Keir, AJE Green, G Giovannoni, and EJ Thompson. A specific ELISA for measuring neurofilament heavy chain phosphoforms. J Immunol Methods, 278:179-190, 2003.

[28] N Norgren, L Rosengren, and T Stigbrand. Elevated neurofilament levels in neurological diseases. Brain Res, 987(1):25-31, October 2003.

[29] A Petzold, K Rejdak, and GT Plant. Axonal degeneration and inflammation in acute optic neuritis. J Neurol Neurosurg Psychiatry, 75:11781180, 2004.

[30] G Shaw, C Yang, R Ellis, K Anderson, et al. Hyperphosphorylated neurofilament NF-H is a serum biomarker for axonal injury. Biochem Biophys Res Comm, 336:1268-1277, 2005.

[31] A. Petzold, D. Stiefel, and A.J. Copp. Amniotic fluid brain-specific proteins are biomarkers for spinal cord injury in experimental myelomeningocele. J Neurochem, 95:594-508, 2005.

[32] MK Lee and DW Cleveland. Neuronal intermediate filaments. Ann Rev Neurosci, 19:187-217, 1996.

[33] G Shaw. Neurofilaments. Springer-Verlag, 1998.

[34] A. Yuan, M.V. Rao, T. Sasaki, Y. Chen, A. Kumar, Veeranna , R.K. Liem, J. Eyer, A.C. Peterson, J.P. Julien, and R.A. Nixon. Alpha-internexin is structurally and functionally associated with the neurofilament triplet proteins in the mature CNS. J Neurosci, 26:10006-10019, 2006.

[35] A Petzold. Encyclopedia of Neuroscience, volume 14, chapter Neurofilaments: A biomarker for axonal degeneration, pages 2768-2772. Springer, Berlin Heidelberg, 1st edition, 2009. Enter text here.

[36] WJA Van Geel, LE Rosengren, and MM Verbeek. An enzyme immunoassay to quantify neurofilament light chain in cerebrospinal fluid. $J$ Immunol Meth, 296:179-185, 2005.

[37] A Petzold and G Shaw. Comparison of two ELISA methods for measuring levels of the phosphorylated neurofilament heavy chain. $J$ Immunol Methods, 319:34-40, 2007.

[38] A Petzold, K Rejdak, A Belli, et al. Axonal pathology in subarachnoid and intracerebral hemorrhage. J Neurotrauma, 22:407-414, 2005.

[39] A Petzold, G Keir, A Kay, M Kerr, and EJ Thompson. Axonal damage and outcome in subarachnoid hemorrhage. J Neurol Neurosurg Psychiatry, 2006. (in press). 
[40] K. Nylen, L.Z. Csajbok, M. Ost, A. Rashid, J.E. Karlsson, K. Blennow, B. Nellgard, and L. Rosengren. CSF -neurofilament correlates with outcome after aneurysmal subarachnoid hemorrhage. Neurosci Lett, 404:132-106, 2006.

[41] H. Rosen, J.E. Karlsson, and L. Rosengren. CSF levels of neurofilament is a valuable predictor of long-term outcome after cardiac arrest. $J$ Neurol Sci, 221:19-24, 2004.

[42] J.T. Wilson, L.E. Pettigrew, and G.M. Teasdale. Structured interviews for the Glasgow Outcome Scale and the extended Glasgow Outcome Scale: guidelines for their use. J Neurotrauma, 15:573-585, 1998.

[43] T. Sugawara, A. Lewen, N. Noshita, Y. Gasche, and P.H. Chan. Effects of global ischemia duration on neuronal, astroglial, oligodendroglial, and microglial reactions in the vulnerable hippocampal CA1 subregion in rats. J Neurotrauma, 19:85-98, 2002.

[44] L.L. Dugan and J.S. Kim-Han. Astrocyte mitochondria in in vitro models of ischemia. J Bioenerg Biomembr, 36:317-321, 2004.

[45] RG Giffard, MC Papadopoulos, JA van Hooft, L Xu, R Giuffrida, and Monyer $\mathrm{H}$. The electrogenic sodium bicarbonate cotransporter: developmental expression in rat brain and possible role in acid vulnerability. $J$ Neursci, 20:1001-1008, 2000.

[46] M Albrechtsen and E Bock. Quantification of glial fibrillary acidic protein (GFAP) in human- body fluids by means of elisa employing a monoclonalantibody. J Neuroimmunol, 8:301-309, 1985.

[47] LE Rosengren, G Ahlsen, M Belfrage, C Gillberg, KG Haglid, and A Hamberger. A sensitive ELISA for glial fibrillary acidic protein - application in CSF of children. J Neurosci Meth, 44:113-119, 1992.

[48] LE Rosengren, C Wikkelso, and L Hagberg. A sensitive ELISA for glial fibrillary acidic protein - application in CSF of adults. I Neuroscience Methods, 51:197-204, 1994.

[49] U Missler, M Wiesmann, et al. Measurement of glial fibrillary acidic protein in human blood: Analytical method and preliminary clinical results. Clin Chem, 45:138-141, 1999.

[50] WJ van Geel, HP de Reus, H Nijzing, MM Verbeek, PE Vos, and KJ Lamers. Measurement of glial fibrillary acidic protein in blood: an analytical method. Clin Chim Acta, 326:151-154, 2002.

[51] K. Nylen, M. Ost, L.Z. Csajbok, I. Nilsson, K. Blennow, B. Nellgard, and L. Rosengren. Increased serum-GFAP in patients with severe traumatic brain injury is related to outcome. J Neurol Sci, 240:85-91, 2006. 
[52] C.A. Gurnett, M. Landt, and M. Wong. Analysis of cerebrospinal fluid glial fibrillary acidic protein after seizures in children. Epilepsia, 44:14551408, 2003.

[53] A Petzold, G Keir, Green AJE, G Giovannoni, and EJ Thompson. An ELISA for glial fibrillary acidic protein. J Immunol Meth, 287:169-177, 2004.

[54] A. Petzold, G. Keir, M. Kerr, A. Kay, N. Kitchen, M. Smith, and E.J. Thompson. Early identification of secondary brain damage in subarachnoid hemorrhage: a role for glial fibrillary acidic protein. J Neurotrauma, 23:1179-1184, 2006.

[55] P.E. Vos, M. van Gils, T. Beems, C. Zimmerman, and M.M. Verbeek. Increased GFAP and S100beta but not NSE serum levels after subarachnoid haemorrhage are associated with clinical severity. Eur $J$ Neurol, 13:632-608, 2006.

[56] P.E. Vos, K.J. Lamers, J.C. Hendriks, M. van Haaren, T. Beems, C. Zimmerman, W. van Geel, H. de Reus, J. Biert, and M.M. Verbeek. Glial and neuronal proteins in serum predict outcome after severe traumatic brain injury. Neurology, 62:1303-1310, 2004.

[57] M.T. Wunderlich, C.W. Wallesch, and M. Goertler. Release of glial fibrillary acidic protein is related to the neurovascular status in acute ischemic stroke. Eur J Neurol, 13:1118-1123, 2006.

[58] C. Foerch, I. Curdt, B. Yan, F. Dvorak, M. Hermans, J. Berkefeld, A. Raabe, T. Neumann-Haefelin, H. Steinmetz, and M. Sitzer. Serum glial fibrillary acidic protein as a biomarker for intracerebral haemorrhage in patients with acute stroke. J Neurol Neurosurg Psychiatry, 77:181104, 2006.

[59] P. Kursula. Structural properties of proteins specific to the myelin sheath. Amino Acids, 34(2):175-185, Feb 2008.

[60] R.P. Berger, T. Dulani, P.D. Adelson, J.M. Leventhal, R. Richichi, and P.M. Kochanek. Identification of inflicted traumatic brain injury in wellappearing infants using serum and cerebrospinal markers: a possible screening tool. Pediatrics, 117:325-332, 2006.

[61] L. Davies, J.G. McLeod, A. Muir, and W.J. Hensley. Diagnostic value of cerebrospinal fluid myelin basic protein in patients with neurological illness. Clin Exp Neurol, 24:5-10, 1987.

[62] J. Matias-Guiu, J. Martinez-Vazquez, A. Ruibal, R. Colomer, M. Boada, and A. Codina. Myelin basic protein and creatine kinase BB isoenzyme as CSF markers of intracranial tumors and stroke. Acta Neurol Scand, 73:461-405, 1986. 
[63] T.W. Noseworthy, B.J. Anderson, A.F. Noseworthy, A. Shustack, R.G. Johnston, K.C. Petruk, and T.A. McPherson. Cerebrospinal fluid myelin basic protein as a prognostic marker in patients with head injury. Crit Care Med, 13:743-706, 1985.

[64] T. Beems, K.S. Simons, W.J. Van Geel, H.P. De Reus, P.E. Vos, and M.M. Verbeek. Serum- and CSF-concentrations of brain specific proteins in hydrocephalus. Acta Neurochir, 145:37-43, 2003.

[65] P.L. Longatti, F. Guida, S. Agostini, B. Carniato, and A. Carteri. The CSF myelin basic protein in pediatric hydrocephalus. Childs Nerv Syst, 10:96-8, 1994.

[66] S.D. Levin, N.R. Hoyle, J.K. Brown, and D.G. Thomas. Cerebrospinal fluid myelin basic protein immunoreactivity as an indicator of brain damage in children. Dev Med Child Neurol, 27:807-813, 1985.

[67] L.N. Sutton, J.H. Wood, B.R. Brooks, S.J. Barrer, M. Kline, and S.R. Cohen. Cerebrospinal fluid myelin basic protein in hydrocephalus. $J$ Neurosurg, 59:467-470, 1983.

[68] Y. Hirashima, S. Endo, S. Nakamura, M. Kurimoto, and A. Takaku. Cerebrospinal fluid membrane-bound tissue factor and myelin basic protein in the course of vasospasm after subarachnoid hemorrhage. Neurol Res, 23:715-720, 2001.

[69] H. Nakagawa, M. Yamada, T. Kanayama, K. Tsuruzono, Y. Miyawaki, K. Tokiyoshi, Y. Hagiwara, and T. Hayakawa. Myelin basic protein in the cerebrospinal fluid of patients with brain tumors. Neurosurgery, 34:825833, 1994.

[70] M Noppe, R Crols, D Andries, and A Lowenthal. Determination in human cerebrospinal fluid of glial fibrillary acidic protein, S-100 and myelin basic protein as indices of non-specific or specific central nervous tissue pathology. Clin Chim Acta, 155:143-50, 1986.

[71] T. Siegal, H. Ovadia, I. Yatsiv, and O. Abramsky. CSF myelin basic protein levels in leptomeningeal metastases. Relationship to disease activity. $J$ Neurol Sci, 78:165-73, 1987.

[72] A. Garcia-Alix, F. Cabanas, A. Pellicer, A. Hernanz, T.A. Stiris, and J. Quero. Neuron-specific enolase and myelin basic protein: relationship of cerebrospinal fluid concentrations to the neurologic condition of asphyxiated full-term infants. Pediatrics, 93:234-240, 1994.

[73] A. Kohlschutter. Myelin basic protein in cerebrospinal fluid from children. Eur J Pediatr, 127:155-61, 1978.

[74] A. Thyss. Myelin basic protein in CSF of children receiving intrathecal chemotherapy. J Clin Oncol, 4:1569-1500, 1986. 
[75] C.R. Pinkerton, J.M. Chessells, and N.R. Hoyle. Myelin basic protein concentrations in the CSF of children receiving methotrexate. J Clin Oncol, 4:112-103, 1986.

[76] E. Neijstrom, D.A. Gabriel, and R.L. Capizzi. High-dose methotrexateinduced neurotoxicity associated with elevation of CSF myelin basic protein. J Clin Oncol, 3:593-504, 1985.

[77] A.W. Clark, S.R. Cohen, M.J. Nissenblatt, and S.K. Wilson. Paraplegia following intrathecal chemotherapy: neuropathologic findings and elevation of myelin basic protein. Cancer, 50:42-7, 1982.

[78] T. Strand, C. Alling, B. Karlsson, I. Karlsson, and B. Winblad. Brain and plasma proteins in spinal fluid as markers for brain damage and severity of stroke. Stroke, 15:138-44, 1984.

[79] J.N. Whitaker, R.P. Lisak, R.M. Bashir, O.H. Fitch, J.M. Seyer, R. Krance, J.A. Lawrence, L.T. Ch'ien, and P. O'Sullivan. Immunoreactive myelin basic protein in the cerebrospinal fluid in neurological disorders. Ann Neurol, 7:58-64, 1980.

[80] KJ Lamers, BG van Engelen, FJ Gabreels, OR Hommes, GF Borm, and RA Wevers. Cerebrospinal neuron-specific enolase, S-100 and myelin basic protein in neurological disorders. Acta Neurol Scand, 92:247-251, 1995.

[81] C. Jacque, A. Delassalle, G. Rancurel, M. Raoul, B. Lesourd, and J.C. Legrand. Myelin basic protein in CSF and blood. Relationship between its presence and the occurrence of a destructive process in the brains of encephalitic patients. Arch Neurol, 39:557-560, 1982.

[82] J. Ruutiainen, T. Arnadottir, G. Molnar, A. Salmi, and H. Frey. Myelin basic protein antibodies in the serum and CSF of multiple sclerosis and subacute sclerosing panencephalitis patients. Acta Neurol Scand, 64:196-206, 1981.

[83] H.S. Panitch, C.J. Hooper, and K.P. Johnson. CSF antibody to myelin basic protein. Measurement in patients with multiple sclerosis and subacute sclerosing panencephalitis. Arch Neurol, 37:206-209, 1980.

[84] C. Alling, B. Karlsson, and B. Vallfors. Increase in myelin basic protein in CSF after brain surgery. J Neurol, 223:225-230, 1980.

[85] J.N. Whitaker. Myelin basic protein in cerebrospinal fluid and other body fluids. Mult Scler, 4:16-21, 1998.

[86] $\mathrm{P}$ Mandel and $\mathrm{P}$ Métais. Les acides nuclétiques du plasma sanguin chez l'homme. C. R. Acad. Sci. Paris, 142:241-243, 1948. 
[87] R. Swaminathan and A.N. Butt. Circulating nucleic acids in plasma and serum: recent developments. Ann N Y Acad Sci, 1075:1-9, 2006.

[88] N.Y. Lam, T.H. Rainer, L.K. Wong, W. Lam, and Y.M. Lo. Plasma DNA as a prognostic marker for stroke patients with negative neuroimaging within the first $24 \mathrm{~h}$ of symptom onset. Resuscitation, 68:71-8, 2006.

[89] L. Fletcher, C.C. Rider, and C.B. Taylor. Enolase isoenzymes. III. Chromatographic and immunological characteristics of rat brain enolase. Biochim Biophys Acta, 452:245-252, 1976.

[90] D. Schmechel, P.J. Marangos, A.P. Zis, M. Brightman, and F.K. Goodwin. Brain endolases as specific markers of neuronal and glial cells. Science, 199:313-305, 1978.

[91] J. Schneider. Tumor markers in detection of lung cancer. Adv Clin Chem, 42:1-41, 2006.

[92] K Mokuno, K Kato, K Kawai, Y Matsuoka, T Yanagi, and I Sobue. Neuronspecific enolase and S-100 protein levels in cerebrospinal fluid of patients with various neurological diseases. J Neurol Sci, 60:443-451, 1983.

[93] C. Jacobi and H. Reiber. Clinical relevance of increased neuron-specific enolase concentration in cerebrospinal fluid. Clin Chim Acta, 177:49-54, 1988.

[94] M. Wong, K. Ess, and M. Landt. Cerebrospinal fluid neuron-specific enolase following seizures in children: role of etiology. J Child Neurol, 17:261-204, 2002.

[95] T. Tanabe, S. Suzuki, K. Hara, S. Shimakawa, E. Wakamiya, and H. Tamai. Cerebrospinal fluid and serum neuron-specific enolase levels after febrile seizures. Epilepsia, 42:504-507, 2001.

[96] J. Correale, A.L. Rabinowicz, C.N. Heck, T.D. Smith, W.J. Loskota, and C.M. DeGiorgio. Status epilepticus increases CSF levels of neuronspecific enolase and alters the blood-brain barrier. Neurology, 50:13881391, 1998.

[97] J. Palmio, J. Peltola, P. Vuorinen, S. Laine, J. Suhonen, and T. Keranen. Normal CSF neuron-specific enolase and S-100 protein levels in patients with recent non-complicated tonic-clonic seizures. J Neurol Sci, 183:2731, 2001.

[98] A.J. Dorta-Contreras, E. Tabio-Valdes, A. Tabio-Valdes, C. DelgadoFernandez, and $\mathrm{H}$. Reiber. Non increased neuron-specific enolase concentration in cerebrospinal fluid during first febrile seizures and a year follow-up in pediatric patients. Arq Neuropsiquiatr, 56:540-504, 1998. 
[99] J.E. Lima, O.M. Takayanagui, L.V. Garcia, and J.P. Leite. Use of neuronspecific enolase for assessing the severity and outcome in patients with neurological disorders. Braz J Med Biol Res, 37:19-26, 2004.

[100] K. Mokuno, K. Kiyosawa, K. Sugimura, T. Yasuda, S. Riku, T. Murayama, T. Yanagi, A. Takahashi, and K. Kato. Prognostic value of cerebrospinal fluid neuron-specific enolase and S-100b protein in Guillain-Barre syndrome. Acta Neurol Scand, 89(1):27-30, January 1994.

[101] J. Karkela, E. Bock, and S. Kaukinen. CSF and serum brain-specific creatine kinase isoenzyme (CK-BB), neuron-specific enolase (NSE) and neural cell adhesion molecule (NCAM) as prognostic markers for hypoxic brain injury after cardiac arrest in man. J Neurol Sci, 116:100-9, 1993.

[102] U.E. Pleines, M.C. Morganti-Kossmann, M. Rancan, H. Joller, O. Trentz, and T. Kossmann. S-100 beta reflects the extent of injury and outcome, whereas neuronal specific enolase is a better indicator of neuroinflammation in patients with severe traumatic brain injury. $J$ Neurotrauma, 18:491-408, 2001.

[103] S.A. Ross, R.T. Cunningham, C.F. Johnston, and B.J. Rowlands. Neuronspecific enolase as an aid to outcome prediction in head injury. $\mathrm{Br} \mathrm{J}$ Neurosurg, 10:471-406, 1996.

[104] R.P. Berger, M.C. Pierce, S.R. Wisniewski, P.D. Adelson, R.S. Clark, R.A. Ruppel, and P.M. Kochanek. Neuron-specific enolase and S100B in cerebrospinal fluid after severe traumatic brain injury in infants and children. Pediatrics, 109:E31, 2002.

[105] P.M. Shore, R.P. Berger, S. Varma, K.L. Janesko, S.R. Wisniewski, R.S. Clark, P.D. Adelson, N.J. Thomas, Y.C. Lai, H. Bayir, and P.M. Kochanek. Biomarkers and Diagnosis; Cerebrospinal Fluid Biomarkers versus Glasgow Coma Scale and Glasgow Outcome Scale in Pediatric Traumatic Brain Injury: The Role of Young Age and Inflicted Injury. J Neurotrauma, 24:75-86, 2007.

[106] BW Moore. A soluble protein characteristic of the nervous system. Biochem Biophys Res Commun, 19:739-744, 1965.

[107] R Donato. S100: a multigenic family of calcium-modulated proteins of the EF-hand type with intracellular and extracellular functional roles. Int J Biochem Cell Biol, 33:637-668, 2001.

[108] M Hattori, A Fujiyama, TD Taylor, et al. The DNA sequence of human chromosome 21. Nature, 405:311-309, 2000.

[109] C.W. Heizmann and J.A. Cox. New perspectives on S100 proteins: a multi-functional $\mathrm{Ca}(2+)-, \mathrm{Zn}(2+)$ - and $\mathrm{Cu}(2+)$-binding protein family. Biometals, 11:383-397, 1998. 
[110] AJE Green, G Keir, and EJ Thompson. A specific and sensitive ELISA for measuring S-100b in cerebrospinal fluid. J Immunol Meth, 205:35-41, 1997.

[111] CJ Sindic, MP Chalon, CL Cambiaso, EC Laterre, and PL Masson. Assessment of damage to the central nervous system by determination of S-100 protein in the cerebrospinal fluid. J Neurol Neurosurg Psychiatry, 45:1130-1105, 1982.

[112] F Michetti, A Massaro, G Russo, and G Rigon. The S-100 antigen in cerebrospinal fluid as a possible index of cell injury in the nervous system. Neurol Sci, 44:259-263, 1980.

[113] C.W. Heizmann. S100B protein in clinical diagnostics: assay specificity. Clin Chem, 50:249-251, 2004.

[114] S. Torabian and M. Kashani-Sabet. Biomarkers for melanoma. Curr Opin Oncol, 17:167-71, 2005.

[115] R. Harpio and R. Einarsson. S100 proteins as cancer biomarkers with focus on S100B in malignant melanoma. Clin Biochem, 37:512-508, 2004.

[116] BJ Steinhoff, H Tumani, M Otto, K Mursch, J Wiltfang, G Herrendorf, HJ Bittermann, K Felgenhauer, W Paulus, and E Markakis. Cisternal S100 protein and neuron-specific enolase are elevated and site-specific markers in intractable temporal lobe epilepsy. Epilepsy Res, 36:75-82, 1999.

[117] M. Stroick, M. Fatar, A. Ragoschke-Schumm, K. Fassbender, T. Bertsch, and M.G. Hennerici. Protein S-100B-a prognostic marker for cerebral damage. Curr Med Chem, 13:3053-3060, 2006.

[118] M. Herrmann and H. Ehrenreich. Brain derived proteins as markers of acute stroke: their relation to pathophysiology, outcome prediction and neuroprotective drug monitoring. Restor Neurol Neurosci, 21:177-90, 2003.

[119] $\mathrm{H}$. Jonsson. S100B and cardiac surgery: possibilities and limitations. Restor Neurol Neurosci, 21:151-107, 2003.

[120] A Petzold, G Keir, D Lim, M Smith, and EJ Thompson. CSF and serum S100B: release and wash-out pattern. Brain Res Bull, 61:281-285, 2003.

[121] AD Kay, A Petzold, M Kerr, G Keir, EJ Thompson, and JA Nicoll. Cerebrospinal fluid apolipoprotein $\mathrm{E}$ concentration decreases after traumatic brain injury. J Neurotrauma, 20:243-250, 2003.

[122] AD Kay, A Petzold, M Kerr, G Keir, E Thompson, and JA Nicoll. Alterations in cerebrospinal fluid apolipoprotein $E$ and amyloid. $J$ Neurotrauma, 20:943-952, 2003. 
[123] T. Hayakata, T. Shiozaki, O. Tasaki, H. Ikegawa, Y. Inoue, F. Toshiyuki, H. Hosotubo, F. Kieko, T. Yamashita, H. Tanaka, T. Shimazu, and H. Sugimoto. Changes in CSF S100B and cytokine concentrations in earlyphase severe traumatic brain injury. Shock, 22:102-7, 2004.

[124] A Kay, A Petzold, M Kerr, G Keir, E Thompson, and J Nicoll. Decreased cerebrospinal fluid apolipoprotein $E$ after subarachnoid hemorrhage: correlation with injury severity and clinical outcome. Stroke, 34:637-642, 2003.

[125] A Kay, A Petzold, M Kerr, G Keir, E Thompson, and J Nicoll. Temporal alterations in cerebrospinal fluid amyloid beta-protein and apolipoprotein E after subarachnoid hemorrhage. Stroke, 34:e240-243, 2003.

[126] M. Goedert, M. G. Spillantini, R. Jakes, D. Rutherford, and R. A. Crowther. Multiple isoforms of human microtubule-associated protein tau: sequences and localization in neurofibrillary tangles of Alzheimer's disease. Neuron, 3(4):519-526, 1989.

[127] M. Vandermeeren, M. Mercken, E. Vanmechelen, J. Six, A. van de Voorde, J.J. Martin, and P. Cras. Detection of tau proteins in normal and Alzheimer's disease cerebrospinal fluid with a sensitive sandwich enzyme-linked immunosorbent assay. J Neurochem, 61:1828-1834, 1993.

[128] K. Jin, A. Takeda, Y. Shiga, S. Sato, A. Ohnuma, H. Nomura, H. Arai, S. Kusunoki, M. Ikeda, and Y. Itoyama. CSF tau protein: a new prognostic marker for Guillain-Barre syndrome. Neurology, 67:1470-1472, 2006.

[129] S.D. Sussmuth, H. Reiber, and H. Tumani. Tau protein in cerebrospinal fluid (CSF): a blood-CSF barrier related evaluation in patients with various neurological diseases. Neurosci Lett, 300:95-8, 2001.

[130] A. Petzold, N. Hinds, N.M. Murray, N.P. Hirsch, D. Grant, G. Keir, E.J. Thompson, and M.M. Reilly. CSF neurofilament levels: a potential prognostic marker in Guillain-Barre syndrome. Neurology, 67:1071-1073, 2006.

[131] M. Ost, K. Nylen, L. Csajbok, A.O. Ohrfelt, M. Tullberg, C. Wikkelso, P. Nellgard, L. Rosengren, K. Blennow, and B. Nellgard. Initial CSF total tau correlates with 1-year outcome in patients with traumatic brain injury. Neurology, 67:1600-1604, 2006.

[132] F.P. Zemlan, W.S. Rosenberg, P.A. Luebbe, T.A. Campbell, G.E. Dean, N.E. Weiner, J.A. Cohen, R.A. Rudick, and D. Woo. Quantification of axonal damage in traumatic brain injury: affinity purification and characterization of cerebrospinal fluid tau proteins. J Neurochem, 72:741-750, 1999. 
[133] F.P. Zemlan, E.C. Jauch, J.J. Mulchahey, S.P. Gabbita, W.S. Rosenberg, S.G. Speciale, and M. Zuccarello. C-tau biomarker of neuronal damage in severe brain injured patients: association with elevated intracranial pressure and clinical outcome. Brain Res, 947:131-109, 2002.

[134] JA Nicoll, GW Roberts, and DI Graham. Apolipoprotein E epsilon 4 allele is associated with deposition of amyloid beta-protein following head injury. Nat Med, 1:135-137, 1995.

[135] K. Blennow, M.J. de Leon, and H. Zetterberg. Alzheimer's disease. Lancet, 368:387-403, 2006.

[136] C. Hesse, L. Rosengren, E. Vanmechelen, H. Vanderstichele, C. Jensen, P. Davidsson, and K. Blennow. Cerebrospinal fluid markers for Alzheimer's disease evaluated after acute ischemic stroke. J Alzheimers Dis, 2:199-206, 2000.

[137] A. Olsson, L. Csajbok, M. Ost, K. Hoglund, K. Nylen, L. Rosengren, B. Nellgard, and K. Blennow. Marked increase of beta-amyloid(1-42) and amyloid precursor protein in ventricular cerebrospinal fluid after severe traumatic brain injury. J Neurol, 251:870-806, 2004.

[138] G. Franz, R. Beer, A. Kampfl, K. Engelhardt, E. Schmutzhard, H. Ulmer, and F. Deisenhammer. Amyloid beta 1-42 and tau in cerebrospinal fluid after severe traumatic brain injury. Neurology, 60:1457-1461, 2003.

[139] M.R. Emmerling, M.C. Morganti-Kossmann, T. Kossmann, P.F. Stahel, M.D. Watson, L.M. Evans, P.D. Mehta, K. Spiegel, Y.M. Kuo, A.E. Roher, and C.A. Raby. Traumatic brain injury elevates the Alzheimer's amyloid peptide A beta 42 in human CSF. A possible role for nerve cell injury. Ann N Y Acad Sci, 903:118-22, 2000.

[140] M. Sjogren, M. Gisslen, E. Vanmechelen, and K. Blennow. Low cerebrospinal fluid beta-amyloid 42 in patients with acute bacterial meningitis and normalization after treatment. Neurosci Lett, 314:33-6, 2001.

[141] K. Blennow and B. Nellgard. Amyloid beta 1-42 and tau in cerebrospinal fluid after severe traumatic brain injury. Neurology, 62:159; author reply 159-60, 2004.

[142] C.A. Raby, M.C. Morganti-Kossmann, T. Kossmann, P.F. Stahel, M.D. Watson, L.M. Evans, P.D. Mehta, K. Spiegel, Y.M. Kuo, A.E. Roher, and M.R. Emmerling. Traumatic brain injury increases beta-amyloid peptide 1-42 in cerebrospinal fluid. J Neurochem, 71:2505-2509, 1998.

[143] J. Pritchard, R.A. Hughes, J.H. Rees, H.J. Willison, and J.A. Nicoll. Apolipoprotein E genotypes and clinical outcome in Guillain-Barre syndrome. J Neurol Neurosurg Psychiatry, 74(7):971-903, July 2003. 
[144] N.A. Martinez-Gonzalez and C.L. Sudlow. Effects of apolipoprotein E genotype on outcome after ischaemic stroke, intracerebral haemorrhage and subarachnoid haemorrhage. J Neurol Neurosurg Psychiatry, 77:1329-1335, 2006.

[145] R. Diaz-Arrastia and V.K. Baxter. Genetic factors in outcome after traumatic brain injury: what the human genome project can teach us about brain trauma. J Head Trauma Rehabil, 21:361-374, 2006.

[146] GM Teasdale, JA Nicoll, G Murray, and M Fiddes. Association of apolipoprotein $\mathrm{E}$ polymorphism with outcome after head injury. Lancet, 350:1069-71, 1997.

[147] J.E. Vance, B. Karten, and H. Hayashi. Lipid dynamics in neurons. Biochem Soc Trans, 34:399-403, 2006.

[148] S. Nishino. The hypocretin/orexin system in health and disease. Biol Psychiatry, 54:87-95, 2003.

[149] S. Nishino and N. Fujiki. Neuropeptides as possible targets in sleep disorders. Expert Opin Ther Targets, 11:37-59, 2007.

[150] C.R. Baumann and C.L. Bassetti. Hypocretins (orexins) and sleep-wake disorders. Lancet Neurol, 4:673-682, 2005.

[151] K Rejdak, A Petzold, Lin L, et al. Decreased CSF hypocretin-1 (orexinA) in patients after acute haemorrhagic brain injury. $J$ Neurol Neurosurg Psychiatry, 76:597-598, 2005.

[152] JA Ogden, E Mee, and M Henning. A prospective study of psychosocial adaptation following subarachnoid haemorrhage. Neuropsychol Rehabil, 4:7-30, 1994.

[153] C.R. Baumann, R. Stocker, H.G. Imhof, O. Trentz, M. Hersberger, E. Mignot, and C.L. Bassetti. Hypocretin-1 (orexin A) deficiency in acute traumatic brain injury. Neurology, 65:147-109, 2005.

[154] B.T. Ang, W.L. Tan, J. Lim, and I. Ng. Cerebrospinal fluid orexin in aneurysmal subarachnoid haemorrhage - a pilot study. J Clin Neurosci, 12:758-762, 2005.

[155] M.J. Doherty, N.F. Watson, D.K. Hallam, W.L. Chandler, and J.r. Longstreth WT. Ventricular cerebrospinal fluid hypocretin-1 inversely correlates with glucose levels in cerebrospinal fluid and serum from patients with neurological injuries. Neurocrit Care, 3:230-203, 2005.

[156] S. Overeem, J. Dalmau, L. Bataller, S. Nishino, E. Mignot, J. Verschuuren, and G.J. Lammers. Hypocretin-1 CSF levels in anti-Ma2 associated encephalitis. Neurology, 62:138-40, 2004. 
[157] P.R. Castillo, E. Mignot, B.K. Woodruff, and B.F. Boeve. Undetectable CSF hypocretin-1 in Hashimoto's encephalopathy associated with coma. Neurology, 62:1909-1900, 2004.

[158] S.P. Grady, S. Nishino, C.A. Czeisler, D. Hepner, and T.E. Scammell. Diurnal variation in CSF orexin-A in healthy male subjects. Sleep, 29:295207, 2006.

[159] S. Cardali and R. Maugeri. Detection of alphall-spectrin and breakdown products in humans after severe traumatic brain injury. $J$ Neurosurg Sci, 50:25-31, 2006.

[160] O. Farkas, B. Polgar, J. Szekeres-Bartho, T. Doczi, J.T. Povlishock, and A. Buki. Spectrin breakdown products in the cerebrospinal fluid in severe head injury-preliminary observations. Acta Neurochir, 147:855861, 2005.

[161] R. Siman, T.K. Mclntosh, K.M. Soltesz, Z. Chen, R.W. Neumar, and V.L. Roberts. Proteins released from degenerating neurons are surrogate markers for acute brain damage. Neurobiol Dis, 16:311-320, 2004.

[162] V. Bennett and D.M. Gilligan. The spectrin-based membrane skeleton and micron-scale organization of the plasma membrane. Annu Rev Cell Biol, 9:27-66, 1993.

[163] J. A. Pineda, S. B. Lewis, A. B. Valadka, L. Papa, H. J. Hannay, S. C. Heaton, J. A. Demery, M. C. Liu, J. M. Aikman, V. Akle, G. M. Brophy, J. J. Tepas, K. K. Wang, C. S. Robertson, and R. L. Hayes. Clinical Significance of alphall-Spectrin Breakdown Products in Cerebrospinal Fluid after Severe Traumatic Brain Injury. J Neurotrauma, 24:354-366, 2007.

[164] M.A. Satchell, Y. Lai, P.M. Kochanek, S.R. Wisniewski, E.L. Fink, N.A. Siedberg, R.P. Berger, S.T. DeKosky, P.D. Adelson, and R.S. Clark. Cytochrome c, a biomarker of apoptosis, is increased in cerebrospinal fluid from infants with inflicted brain injury from child abuse. J Cereb Blood Flow Metab, 25:919-927, 2005.

[165] Y. Seki, M. Kimura, N. Mizutani, M. Fujita, Y. Aimi, and Y. Suzuki. Cerebrospinal fluid taurine after traumatic brain injury. Neurochem Res, 30:123-108, 2005.

[166] J.F. Stover and A.W. Unterberg. Increased cerebrospinal fluid glutamate and taurine concentrations are associated with traumatic brain edema formation in rats. Brain Res, 875:51-5, 2000.

[167] J.F. Stover, M.C. Morganti-Kosmann, P.M. Lenzlinger, R. Stocker, O.S. Kempski, and T. Kossmann. Glutamate and taurine are increased in ventricular cerebrospinal fluid of severely brain-injured patients. J Neurotrauma, 16:135-42, 1999. 
[168] C. Kirchhoff, J. Stegmaier, V. Bogner, S. Buhmann, T. Mussack, U. Kreimeier, W. Mutschler, and P. Biberthaler. Intrathecal and systemic concentration of NT-proBNP in patients with severe traumatic brain injury. J Neurotrauma, 23:943-909, 2006.

[169] M. Majetschak, D.R. King, U. Krehmeier, L.T. Busby, C. Thome, S. Vajkoczy, and K.G. Proctor. Ubiquitin immunoreactivity in cerebrospinal fluid after traumatic brain injury: clinical and experimental findings. Crit Care Med, 33:1589-1594, 2005.

[170] A. Aitken. 14-3-3 proteins: a historic overview. Semin Cancer Biol, 16:162-72, 2006.

[171] G.P. van Heusden. 14-3-3 proteins: regulators of numerous eukaryotic proteins. IUBMB Life, 57:623-609, 2005.

[172] D. Bridges and G.B. Moorhead. 14-3-3 proteins: a number of functions for a numbered protein. Sci STKE, 2005:re10, 2005.

[173] P. Mhawech. 14-3-3 proteins-an update. Cell Res, 15:228-236, 2005.

[174] P.F. Boston, P. Jackson, and R.J. Thompson. Human 14-3-3 protein: radioimmunoassay, tissue distribution, and cerebrospinal fluid levels in patients with neurological disorders. J Neurochem, 38:1475-1482, 1982.

[175] J. Satoh, K. Kurohara, M. Yukitake, and Y. Kuroda. The 14-3-3 protein detectable in the cerebrospinal fluid of patients with prion-unrelated neurological diseases is expressed constitutively in neurons and glial cells in culture. Eur Neurol, 41:216-225, 1999.

[176] A.J. Green, S. Ramljak, W.E. Muller, R.S. Knight, and H.C. Schroder. 14-3-3 in the cerebrospinal fluid of patients with variant and sporadic Creutzfeldt-Jakob disease measured using capture assay able to detect low levels of 14-3-3 protein. Neurosci Lett, 324:57-60, 2002.

[177] AJ Green, EJ Thompson, GE Stewart, M Zeidler, JM McKenzie, MA MacLeod, JW Ironside, RG Will, and RS Knight. Use of 14-33 and other brain-specific proteins in CSF in the diagnosis of variant Creutzfeldt-Jakob disease. J Neurol Neurosurg Psychiatry, 70:744-748, 2001.

[178] A. Bersano, M. Fiorini, S. Allaria, G. Zanusso, E. Fasoli, M. Gelati, H. Monaco, G. Squintani, S. Monaco, and E. Nobile-Orazio. Detection of CSF 14-3-3 protein in Guillain-Barre syndrome. Neurology, 67:22112206, 2006.

[179] T. Vander, C. Hallevy, I. Alsaed, S. Valdman, G. Ifergane, and I. Wirguin. 14-3-3 protein in the CSF of a patient with Hashimoto's encephalopathy. J Neurol, 251:1273-1204, 2004. 
[180] L.E. Hernandez Echebarria, A. Saiz, F. Graus, J. Tejada, J.M. Garcia, B. Clavera, and F. Fernandez. Detection of 14-3-3 protein in the CSF of a patient with Hashimoto's encephalopathy. Neurology, 54:1539-1540, 2000.

[181] S. Bonora, G. Zanusso, R. Raiteri, S. Monaco, A. Rossati, S. Ferrari, M. Boffito, S. Audagnotto, A. Sinicco, N. Rizzuto, E. Concia, and G. Di Perri. Clearance of 14-3-3 protein from cerebrospinal fluid heralds the resolution of bacterial meningitis. Clin Infect Dis, 36:1492-1405, 2003.

[182] J. Finsterer and T. Voigtlander. Elevated 14-3-3 protein and axonal loss in immunoglobulin-responsive, idiopathic acute transverse myelitis. Clin Neurol Neurosurg, 105:18-22, 2002.

[183] G. Grigelioniene, M. Blennow, C. Torok, G. Fried, I. Dahlin, U. Lendahl, and $\mathrm{H}$. Lagercrantz. Cerebrospinal fluid of newborn infants contains a deglycosylated form of the intermediate filament nestin. Pediatr Res, 40:809-814, 1996.

[184] H. Abboud, J. Labreuche, E. Meseguer, P.C. Lavallee, O. Simon, J.M. Olivot, M. Mazighi, M. Dehoux, J. Benessiano, P.G. Steg, and P. Amarenco. Ischemia-modified albumin in acute stroke. Cerebrovasc Dis, 23:216-220, 2007.

[185] E.C. Jauch, C. Lindsell, J. Broderick, S.C. Fagan, B.C. Tilley, and S.R. Levine. Association of serial biochemical markers with acute ischemic stroke: the National Institute of Neurological Disorders and Stroke recombinant tissue plasminogen activator Stroke Study. Stroke, 37:25082513, 2006.

[186] M. Sartori, V. Benetton, A.M. Carraro, L.A. Calo, L. Macchini, V. Giantin, F. Tosato, A.C. Pessina, and A. Semplicini. Blood pressure in acute ischemic stroke and mortality: a study with noninvasive blood pressure monitoring. Blood Press Monit, 11:199-205, 2006.

[187] G. Lippi, G.L. Salvagno, M. Montagnana, F. Schena, F. Ballestrieri, and G.C. Guidi. Influence of physical exercise and relationship with biochemical variables of NT-pro-brain natriuretic peptide and ischemia modified albumin. Clin Chim Acta, 367:175-80, 2006.

[188] G. Lippi, G. Brocco, G.L. Salvagno, M. Montagnana, F. Dima, and G.C. Guidi. High-workload endurance training may increase serum ischemiamodified albumin concentrations. Clin Chem Lab Med, 43:741-704, 2005.

[189] A. Cherubini, C. Ruggiero, M.C. Polidori, and P. Mecocci. Potential markers of oxidative stress in stroke. Free Radic Biol Med, 39:841-852, 2005. 
[190] K Rejdak, A Petzold, MA Sharpe, et al. Serum and urine nitrate and nitrite are not reliable indicators of intrathecal nitric oxide production in acute brain injury. J Neurol Sci, 208(1-2):1-7, April 2003.

[191] KM Miranda, MG Espey, and DA Wink. A rapid, simple spectrophotometric method for simultaneous detection of nitrate and nitrite. Nitric Oxide, 5:62-71, 2001.

[192] R.G. Keynes and J. Garthwaite. Nitric oxide and its role in ischaemic brain injury. Curr Mol Med, 4:179-91, 2004.

[193] S. Moncada and J.P. Bolanos. Nitric oxide, cell bioenergetics and neurodegeneration. J Neurochem, 97:1676-1689, 2006.

[194] M.A. Moro, A. Cardenas, O. Hurtado, J.C. Leza, and I. Lizasoain. Role of nitric oxide after brain ischaemia. Cell Calcium, 36:265-275, 2004.

[195] B Meldrum and J Garthwaite. Excitatory amino acid neurotoxicity and neurodegenerative disease. Trends Pharmacol Sci, 11:379-387, 1990.

[196] A.M. Palmer, D.W. Marion, M.L. Botscheller, D.M. Bowen, and S.T. DeKosky. Increased transmitter amino acid concentration in human ventricular CSF after brain trauma. Neuroreport, 6:153-106, 1994.

[197] H. Zhang, X. Zhang, T. Zhang, and L. Chen. Excitatory amino acids in cerebrospinal fluid of patients with acute head injuries. Clin Chem, 47:1458-1462, 2001.

[198] J.F. Stover, B. Schoning, T.F. Beyer, C. Woiciechowsky, and A.W. Unterberg. Temporal profile of cerebrospinal fluid glutamate, interleukin- 6 , and tumor necrosis factor-alpha in relation to brain edema and contusion following controlled cortical impact injury in rats. Neurosci Lett, 288:25-8, 2000.

[199] R.A. Ruppel, P.M. Kochanek, P.D. Adelson, M.E. Rose, S.R. Wisniewski, M.J. Bell, R.S. Clark, D.W. Marion, and S.H. Graham. Excitatory amino acid concentrations in ventricular cerebrospinal fluid after severe traumatic brain injury in infants and children: the role of child abuse. $J$ Pediatr, 138:18-25, 2001.

[200] M.C. Polidori, A. Cherubini, W. Stahl, U. Senin, H. Sies, and P. Mecocci. Plasma carotenoid and malondialdehyde levels in ischemic stroke patients: relationship to early outcome. Free Radic Res, 36:265-208, 2002.

[201] J.W. Phillis and M.H. O'Regan. The role of phospholipases, cyclooxygenases, and lipoxygenases in cerebral ischemic/traumatic injuries. Crit Rev Neurobiol, 15:61-90, 2003. 
[202] J.D. Morrow, K.E. Hill, R.F. Burk, T.M. Nammour, K.F. Badr, and 2nd Roberts LJ. A series of prostaglandin F2-like compounds are produced in vivo in humans by a non-cyclooxygenase, free radical-catalyzed mechanism. Proc Natl Acad Sci U S A, 87:9383-9307, 1990.

[203] J. Rokach, S. Kim, S. Bellone, J.A. Lawson, D. Pratico, W.S. Powell, and G.A. FitzGerald. Total synthesis of isoprostanes: discovery and quantitation in biological systems. Chem Phys Lipids, 128:35-56, 2004.

[204] S. Basu and J. Helmersson. Factors regulating isoprostane formation in vivo. Antioxid Redox Signal, 7:221-235, 2005.

[205] J.L. Cracowski. Isoprostanes: an emerging role in vascular physiology and disease? Chem Phys Lipids, 128:75-83, 2004.

[206] C.L. Lin, Y.T. Hsu, T.K. Lin, J.D. Morrow, J.C. Hsu, Y.H. Hsu, T.C. Hsieh, P.K. Tsay, and H.C. Yen. Increased levels of F2-isoprostanes following aneurysmal subarachnoid hemorrhage in humans. Free Radic Biol Med, 40:1466-1473, 2006.

[207] H. Bayir, D.W. Marion, A.M. Puccio, S.R. Wisniewski, K.L. Janesko, R.S. Clark, and P.M. Kochanek. Marked gender effect on lipid peroxidation after severe traumatic brain injury in adult patients. J Neurotrauma, 21:18, 2004.

[208] S. Varma, K.L. Janesko, S.R. Wisniewski, H. Bayir, P.D. Adelson, N.J. Thomas, and P.M. Kochanek. F2-isoprostane and neuron-specific enolase in cerebrospinal fluid after severe traumatic brain injury in infants and children. J Neurotrauma, 20:781-706, 2003.

[209] A.K. Wagner, H. Bayir, D. Ren, A. Puccio, R.D. Zafonte, and P.M. Kochanek. Relationships between cerebrospinal fluid markers of excitotoxicity, ischemia, and oxidative damage after severe TBI: the impact of gender, age, and hypothermia. J Neurotrauma, 21:125-36, 2004.

[210] J.H. Veerkamp and A.W. Zimmerman. Fatty acid-binding proteins of nervous tissue. J Mol Neurosci, 16:133-42; discussion 151-7, 2001.

[211] P. Steinacker, B. Mollenhauer, M. Bibl, L. Cepek, H. Esselmann, P. Brechlin, P. Lewczuk, S. Poser, H.A. Kretzschmar, J. Wiltfang, C. Trenkwalder, and M. Otto. Heart fatty acid binding protein as a potential diagnostic marker for neurodegenerative diseases. Neurosci Lett, 370:36-9, 2004.

[212] M.T. Wunderlich, T. Hanhoff, M. Goertler, F. Spener, J.F. Glatz, C.W. Wallesch, and M.M. Pelsers. Release of brain-type and heart-type fatty acid-binding proteins in serum after acute ischaemic stroke. $J$ Neurol, 252:718-724, 2005. 
[213] C.G. Zimmermann-Ivol, P.R. Burkhard, J. Le Floch-Rohr, L. Allard, D.F. Hochstrasser, and J.C. Sanchez. Fatty acid binding protein as a serum marker for the early diagnosis of stroke: a pilot study. Mol Cell Proteomics, 3:66-72, 2004.

[214] S.M. Allan, P.J. Tyrrell, and N.J. Rothwell. Interleukin-1 and neuronal injury. Nat Rev Immunol, 5:629-640, 2005.

[215] A Petzold, P Downie, and M Smith. Critical illness brain syndrome (CIBS) - an underestimated entity? Crit Care Med, 33:1464, 2005.

[216] R.O. Hopkins and J.C. Jackson. Long-term neurocognitive function after critical illness. Chest, 130:869-878, 2006.

[217] R.D. Stevens and P.J. Pronovost. The spectrum of encephalopathy in critical illness. Semin Neurol, 26:440-451, 2006.

[218] A. Conti, Y. Sanchez-Ruiz, A. Bachi, L. Beretta, E. Grandi, M. Beltramo, and M. Alessio. Proteome study of human cerebrospinal fluid following traumatic brain injury indicates fibrin(ogen) degradation products as trauma-associated markers. J Neurotrauma, 21:854-863, 2004.

[219] W.M. Gao, M.S. Chadha, R.P. Berger, G.S. Omenn, D.L. Allen, M. Pisano, P.D. Adelson, R.S. Clark, L.W. Jenkins, and P.M. Kochanek. Biomarkers and Diagnosis; A Gel-Based Proteomic Comparison of Human Cerebrospinal Fluid between Inflicted and Non-Inflicted Pediatric Traumatic Brain Injury. J Neurotrauma, 24:43-53, 2007.

[220] J.A. Burgess, P. Lescuyer, A. Hainard, P.R. Burkhard, N. Turck, P. Michel, J.S. Rossier, F. Reymond, D.F. Hochstrasser, and J.C. Sanchez. Identification of brain cell death associated proteins in human. J Proteome Res, 5:1674-1681, 2006.

[221] JW Albers and JJ Kelly Jr. Acquired inflammatory demyelinating polyneuropathies: clinical and electrodiagnostic features. Muscle Nerve, 12:435451, 1989. 